\title{
A Closed-Loop Supply Chain with Trade-In Strategy under Retail Competition
}

\author{
Yanting Huang ${ }^{1,2}$ \\ ${ }^{1}$ School of Management, Hangzhou Dianzi University, Hangzhou 310018, China \\ ${ }^{2}$ School of Management, Huazhong University of Science and Technology, Wuhan 430074, China \\ Correspondence should be addressed to Yanting Huang; ythuang4028@hust.edu.cn
}

Received 29 September 2017; Revised 10 December 2017; Accepted 17 December 2017; Published 18 January 2018

Academic Editor: Vladimir Turetsky

Copyright (c) 2018 Yanting Huang. This is an open access article distributed under the Creative Commons Attribution License, which permits unrestricted use, distribution, and reproduction in any medium, provided the original work is properly cited.

\begin{abstract}
This paper investigates a closed-loop supply chain (CLSC) consisting of a manufacturer and two competing retailers who collect used products through trade-in strategy. Three remanufacturing models with trade-in strategy have been developed: (1) the manufacturer implements trade-in strategy (Model M), (2) single retailer collects used products through trade-in strategy (Model SR), and (3) two retailers undertake trade-in activities (Model TR). We analyze the impact of trade-in strategy on equilibrium decisions and chain members' profits when retailing is competitive. We show that, as for the manufacturer, he prefers the case where trade-in is implemented by himself due to the direct benefits from remanufacturing, and the case of single retailer implementing trade-in strategy is the most unfavorable for the environment. We also show that, if the net value of a used product is sufficiently large, the retailer only selling products benefits from the case of the manufacturer implementing trade-in strategy because the manufacturer can coordinate both the forward and reverse flows, and Model M dominates Model TR for the retailer who undertakes both product sales and trade-in strategy. Moreover, a larger trade-in rebate can be achieved when two retailers simultaneously conduct trade-in strategy due to the intense competition between two retailers.
\end{abstract}

\section{Introduction}

The importance of the environmental performance and the economic benefit of remanufacturing have drawn extensive attention in recent years [1-4]. Remanufacturing, as one important way of product recovery options [5], can not only reduce natural resources and recover value from used products, but also cut down landfill space and air pollution [6]. Some green organizations have also launched recycling and remanufacturing feasibility. Many companies have begun to carry out collecting and remanufacturing strategies in various forms and have already derived substantial profits from used products with high residual value [7]. For example, many manufacturers, such as HP, Caterpillar, and Xerox, have joined the ranks of firms performing remanufacturing, and $30 \sim 70 \%$ cost savings can be reached from remanufactured products more than that from new products [8]. Also, Home Depot has returned used products over $10 \%$ of sales [9].
On the other hand, once those obsolete products have been handled incorrectly at the end-of-life, more environmental problems would be brought up even than processing of raw materials. Responding to increased environmental pressure, related take-back legislations have been enacted by governments in many countries. Popular legislations under Extended Producer Responsibility [10] aim to hold producers physically and financially responsible for the environmental impact of their used products. Such legislations have been applied in many industries, such as automotive, batteries, and electronic waste (e-waste). The first US take-back law was passed in Maine in 2004 and many other states such as Washington and California take part in the remanufacturing activities soon [11]. To entice consumers to return used products, in 2012, the Chinese government put forward a trade-in subsidy for household appliances and automobiles. Take a real case: Panasonic Co. adopts the trade-in method to simulate customers to recycle their used computers [12]. Apple also offers a $10 \%$ discount for the consumers who 
purchase a new iPod through trade-in strategy. Up to now, the large retailers Best Buy and Amazon have implemented tradein strategy for many products, such as personal computers, printers, and cellphones [13]. It has been revealed that the trade-in strategy, as one efficient collection way, is beneficial for the environment [14].

One question may arise naturally: Who should implement the trade-in strategy? Actually, both manufacturers and retailers are engaged in trade-in activities, and the competition between them plays an important role on supply chain performance. In real cases, in the appliance industry, manufacturers recycle used appliances from consumers, who can also acquire some subsidies as a reward. For instance, Haier directly collects their used air conditioners and refrigerators from consumers. Regarding the case of retailer collecting, the large computer manufacturers Lenovo and ASUS regularly seek to outsource trade-in activities to different retailers, and the famous American technology company Kodak also recycles used products through retailers [15]. Although several scholars have studied related issues of tradein strategy $[16,17]$, the case where one manufacturer and two retailers implement trade-in strategy under competition in a closed-loop supply chain (CLSC) is still rarely considered. To this end, we focus on the influence of trade-in strategy on the chain members' decisions when retailing is competitive and compare equilibrium pricing strategies of each trade-in scheme in the CLSC. Specifically, we investigate three tradein schemes when there exists retailers' competition; namely, (1) the manufacturer undertakes trade-in activities, (2) single retailer implements trade-in strategy, and (3) two retailers simultaneously conduct trade-in activities. This paper for the first time inserts the retailers' competition into tradein strategy and explores which trade-in scheme allows the optimal pricing decisions and profits of chain members. We aim to address the following issues:

(1) What are equilibrium decisions in centralized and decentralized models with trade-in strategy?

(2) From the perspectives of chain members and consumers, which is the optimal trade-in scheme when retailing is competitive?

(3) How do different trade-in strategies influence the environmental performance?

The remainder of this paper is organized as follows. Section 2 discusses the relevant literature. Related notation and problem description are presented in Section 3. In Section 4, we propose and address the centralized model and three decentralized trade-in models. We compare four models with respect to equilibrium decisions and chain members' profits and analyze the impact of different trade-in strategies on environmental performance in Section 5. Section 6 provides additional numerical examples. The conclusion and further research directions are in Section 7. All proofs of this paper are provided in the appendix.

\section{Literature Review}

This paper is related to the literature on remanufacturing in CLSCs. In this area, recycling is an important branch of remanufacturing and has been extensively studied. Savaskan et al. [15] elaborately explore three kinds of recycling modes, namely, manufacturer collection, retailer collection, and third-party collection, and assert that the retailer is the effective collector for the manufacturer. Regarding different channel power, Gao et al. [18] investigate three channel structures, including manufacturer Stackelberg, vertical Nash, and retailer Stackelberg, and discuss the impact of different channel power structures on collection effort, sales effort, and pricing decisions. Moreover, from the viewpoint of manufacturing-remanufacturing conflict, Zhou et al. [19] study the manufacturer's choices about centralized and decentralized control mode in terms of collection and processing. The common element of these papers is that only single chain member is engaged in remanufacturing activities.

Subsequently, we turn to the consideration of the competition among chain members in a CLSC; Wu [8] considers two manufacturers' competition from the dual perspectives of price and service and suggests that service competition is profitable to the retailer and is detrimental to the manufacturers. In a single- and two-period setting, Mitra [20] answers the question whether remanufacturing is profitable in a duopoly competitive environment and confirms that remanufacturing is always beneficial for the manufacturer. Further, Hsieh et al. [21] demonstrate the competition between multiple manufacturers under uncertain demand. In their view, an equilibrium state can be achieved in the decentralized system when certain profit allocation conditions are satisfied. Atasu et al. [6] study the impact of market competition, product lifecycle, and green segments on remanufacturing system and show that remanufacturing can be regarded as an effective marketing strategy when there exists competition.

Taking the competition between original equipment manufacturers (OEMs) and remanufacturers into account, Ferrer and Swaminathan [22] explore the effective policies between an independent operator (IO) and an OEM in two-period and multiperiod remanufacturing scenarios and show that the OEM prefers to provide the remanufactured products with a lower price. Örsdemir et al. [23] also present the competition between an OEM and a dependent remanufacturer with respect to their production quantities. Additionally, $\mathrm{Wu}$ [24] investigates equilibrium prices and incentives when an OEM and a remanufacturer compete in sales market and recycling market. Qiang [25] analyzes the effect of consumer preferences and the remanufactureability design on manufacturers' competition in two-period CLSC.

Although manufacturers' competition has been addressed because of its popularity and reality, retailers' competition can also affect the remanufacturing process. Savaskan and van Wassenhove [26] develop recycling models when there exists the competition between two retailers and examine the effect of the allocation of product collection on retailers' strategic behavior. Considering a fuzzy environment, Wei and Zhao [27] analyze pricing decisions of two competitive retailers and one manufacturer and attain the optimal expressions of retail prices, wholesale price, and collection rate by using the fuzzy theory. Afterward, they [28] develop five models based on different remanufacturing strategies in two competing supply chains. 
Our work is most closely related to the stream of remanufacturing with trade-ins, and a handful of papers have been carried out in operations management. Ma et al. [29] study chain members' decisions with government trade-in consumption subsidy when the retailer and the $e$-tailer simultaneously exist. Miao et al. [30] propose three collection models and discuss three types of trade-in strategies: no collection, partial collection, and full collection. Their research identifies the optimal conditions and models from the perspective of chain members and environmental performance. Further, they [31] examine how carbon tax policy and cap and trade program influence the manufacturer's decisions and suggest that appropriate government subsidy schemes can improve the manufacturer's profits and reduce total carbon emissions under well-designed regulations. Very recently, Zhu et al. [32] demonstrate two firms' optimal decisions in a duopoly situation with trade-ins. In contrast to the above papers, this paper integrates retailers' competition with trade-in strategy and explores the impact of different trade-in strategies on pricing decisions under competition. Moreover, we analyze three scenarios in which the manufacturer, single retailer, and two retailers undertake trade-in activities when there exists retailers' competition and characterize chain members' equilibrium decisions of prices, quantities, and profits under each scenario.

\section{Problem Description and Assumptions}

This paper considers a CLSC consisting of one manufacturer and two retailers and analyzes three trade-in schemes when retailing is competitive. We first investigate the centralized model, in which the manufacturer and the retailers are responsible for production producing, selling, and trade-in activities as a whole (Model C, Figure 1(a)). Additionally, three decentralized trade-in models are discussed; namely, the manufacturer, single retailer, and two retailers implement trade-in strategy, respectively (i.e., Model M, Figure 1(b); Model SR, Figure 1(c); Model TR, Figure 1(d)). The parameters in the paper are described in "Notations" section shown at the end of the paper.

We assume that there exist two types of consumers: the primary consumers and the replacement consumers who already own used products. The market size is $\alpha+\beta$, where $\alpha$ and $\beta$ represent the primary consumers and the replacement consumers, respectively. Both consumers are heterogeneous with their willingness to pay $\theta$, which is uniformly distributed in the interval $[0,1]$. In addition, the primary consumers buy a new product at a retail price of $p_{n}$ and the net utility is nonnegative; that is, $U_{n}=\theta-p_{n} \geq 0$. Therefore, the demand function of primary consumers can be denoted as follows:

$$
Q_{n}=\alpha \int_{p_{n}}^{1} d \theta=\alpha\left(1-p_{n}\right)
$$

Then the reverse demand function can be solved as $p_{n}=$ $1-\left(q_{1 n}+q_{2 n}\right) / \alpha$. Here, subscripts 1 and 2 denote the retailer 1 and the retailer 2 , respectively.

The replacement consumers have two options: trade-in or continuing use. To allow product depreciation and quality deterioration with use, assuming the quality retention index $\delta$, the utility of a used product is $(1-\theta) \delta$, where $0 \leq \delta \leq 1$. Given the trade-in rebate $p_{0}$ and the trade-in subsidy from the government $S$, the replacement consumer chooses trade-in if the utility $U_{t}=\theta-p_{n}+p_{0}+s>(1-\delta) \theta$. On the contrary, the consumer continues to use the old product. Thus, the demand of trade-in consumers can be expressed as follows:

$$
Q_{t}=\beta \int_{\left(p_{n}-p_{0}-s\right) / \delta}^{1} d \theta=\beta\left(1-\frac{p_{n}-p_{0}-s}{\delta}\right)
$$

Subsequently, we can attain the trade-in rebate based on (2), and the value is given by $p_{0}=1-\left(q_{1 n}+q_{2 n}\right) / \alpha-s-$ $\delta+\delta Q_{t} / \beta$. We consider two parameters, the trade-in subsidy $s$ and the salvage value of a used product $v$. Hence, for the whole supply chain and consumers, the net value of a used product from trade-in activities is $b$ (i.e., $b=v+s$ ). We analyze and compare the models with respect to the prices, demands, and chain members' profits with different strategy space of parameter $b$.

It is generally considered that the procedure of remanufacturing is more positive for the environment than fabricating new products [33]. And it is obvious that continuing to use old products is harmful to the environment [30]. Therefore, the environmental performance is proportional to the demand of replacement consumers in the whole supply chain, and whether or not trade-in policy improves environmental performance depends on the demand of replacement consumers.

\section{Closed-Loop Supply Chain Models}

In this section, we present the centralized model and three decentralized models with trade-in strategy. The manufacturer, as the channel leader, has extreme power in the CLSC. We explore how equilibrium decisions affect the retail price, the trade-in rebate, the demands of primary consumers, and trade-in consumers in different trade-in schemes.

4.1. The Centralized Model (Model C). The centralized model, as a benchmark, is compared with three decentralized models with respect to chain members' pricing decisions and profits. Moreover, the central planner decides the retail price $\left(p_{n}\right)$ and the trade-in rebate $\left(p_{0}\right)$. Mathematically, this approach is equivalent to determining the demand of primary consumers $\left(Q_{n}\right)$ and the demand of trade-in consumers $\left(Q_{t}\right)$ to maximize the profit. The optimal problem can be solved as follows:

$$
\Pi^{\mathrm{C}}=\max _{\mathrm{Q}_{n}, \mathrm{Q}_{t}}\left\{\left(p_{n}-c_{n}\right) Q_{n}+\left(p_{n}-c_{n}+v-p_{0}\right) Q_{t}\right\} .
$$

Proposition 1. In Model C, the optimal policies are as follows:

$$
\begin{aligned}
Q_{n}^{C *} & =\frac{\alpha\left(1-c_{n}\right)}{2}, \\
Q_{t}^{C *} & =\frac{\beta\left(v+\delta+s-c_{n}\right)}{2 \delta} .
\end{aligned}
$$




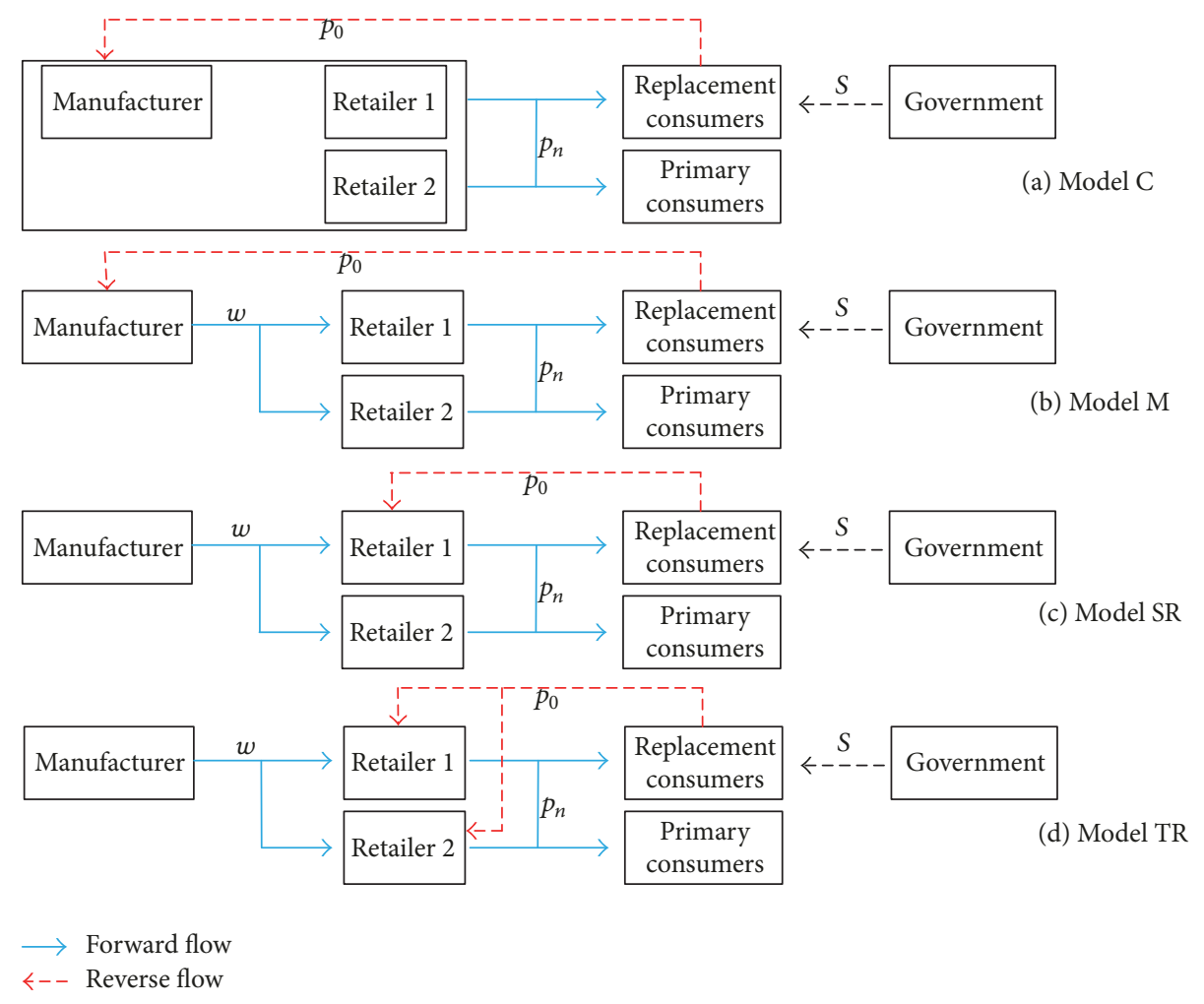

FIGURE 1: Closed-loop supply chain models with remanufacturing.

Subsequently, the optimal prices in Model C can be obtained as follows:

$$
\begin{aligned}
& p_{n}^{\mathrm{C} *}=\frac{1+c_{n}}{2}, \\
& p_{0}^{\mathrm{C} *}=\frac{v-\delta-s+1}{2} .
\end{aligned}
$$

Substituting $Q_{n}^{\mathrm{C*}}$ and $Q_{t}^{\mathrm{C*}}$ into (3), we can get the optimal profit as follows:

$$
\Pi^{\mathrm{C} *}=\frac{\alpha\left(1-c_{n}\right)^{2}}{4}+\frac{\beta\left(v+\delta+s-c_{n}\right)^{2}}{4 \delta} .
$$

According to the above analysis, we find that $Q_{t}^{\mathrm{C} *}$ and $\Pi^{\mathrm{C} *}$ are increasing in $v$ and $s$, while $p_{0}^{\mathrm{C} *}$ is increasing in $v$ and decreasing in $s$. Additionally, $p_{0}^{\mathrm{C} *}$ and $Q_{n}^{\mathrm{C} *}$ have no relationships with $v$ and $s$. Therefore, we can conclude that a higher salvage value $v$ and a larger subsidy $s$ contribute to the profitability of the reverse supply chain and the trade-in activities in Model C.

\subsection{The Manufacturer Implementing Trade-In Strategy (Model} $M)$. In this case, the manufacturer is engaged in producing new products and collecting used products through trade-in strategy, and two retailers are only responsible for product sales. The interaction between them can be modeled as a Stackelberg game. First, the manufacturer takes two retailers' response functions into consideration to determine the demand of trade-in consumers $Q_{t}$, the wholesale price $w$, and the discount price $p_{t}$. Second, the retailers decide the demand of primary consumers $q_{1 n}$ and $q_{2 n}$, respectively. We can acquire the equilibrium decisions by backward induction.

The retailers' optimal problems can be written as follows:

$$
\begin{aligned}
& \Pi_{R_{1}}^{\mathrm{M}}=\max _{q_{1 n}}\left(p_{n}-w\right) q_{1 n}, \\
& \Pi_{R_{2}}^{\mathrm{M}}=\max _{q_{2 n}}\left(p_{n}-w\right) q_{2 n} .
\end{aligned}
$$

And the manufacturer's objective function can be transformed into

$$
\begin{aligned}
\Pi_{M}^{\mathrm{M}}=\max _{w, Q_{t}, p_{t}} & \left\{\left(w-c_{n}\right) Q_{n}+\left(p_{t}-c_{n}+v-p_{0}\right) Q_{t}\right\} \\
\text { s.t. } & Q_{n}=q_{1 n}+q_{2 n} \geq 0, \\
& w \leq p_{t} \leq p_{n} .
\end{aligned}
$$

The discount price $p_{t}$ needs to satisfy $w \leq p_{t} \leq$ $p_{n}$. In other words, the discount price directly from the manufacturer to consumers is no more than the retail price from the retailers to consumers and is higher than the wholesale price. Based on this constraint, we can solve the optimal problem by KKT necessary conditions, and then we have Proposition 2. 
Proposition 2. In Model M, the optimal policies are as follows:

$$
\begin{aligned}
w^{M *} & =\frac{1+c_{n}}{2}, \\
p_{t}^{M *} & =p_{n}^{M *}=\frac{2+c_{n}}{3}, \\
Q_{t}^{M *} & =\frac{\beta\left(v+\delta+s-c_{n}\right)}{2 \delta}, \\
q_{2 n}^{M *} & =q_{1 n}^{M *}=\frac{\alpha\left(1-c_{n}\right)}{6}, \\
Q_{n}^{M *} & =\frac{\alpha\left(1-c_{n}\right)}{3} .
\end{aligned}
$$

Proposition 2 indicates that (1) the demand of replacement consumers in Model M is the same as that in Model $\mathrm{C}$, and (2) the ratio of the demand of primary consumers between Model C and Model M is equal to 3/2. The trade-in rebate can be decided by the above equations as follows:

$$
p_{0}^{\mathrm{M} *}=\frac{3 v-3 \delta-3 s-c_{n}+4}{6} .
$$

Taking the values of the parameters back into (7) and (8), we can obtain the optimal profits as follows:

$$
\begin{aligned}
& \Pi_{R_{1}}^{\mathrm{M} *}=\Pi_{R_{2}}^{\mathrm{M} *}=\frac{\alpha\left(1-c_{n}\right)^{2}}{36}, \\
& \Pi_{M}^{\mathrm{M} *}=\frac{\alpha\left(1-c_{n}\right)^{2}}{6}+\frac{\beta\left(v+\delta+s-c_{n}\right)^{2}}{4 \delta} .
\end{aligned}
$$

From the perspective of monotonicity, the manufacturer's profit increases in the discount price $p_{t}$. When $p_{t}$ reaches the maximum value (i.e., $p_{t}=p_{n}$ ), the manufacturer's profit can be the largest. It is found that $Q_{t}^{\mathrm{M} *}$ and $\Pi_{M}^{\mathrm{M} *}$ are increasing in $v$ and $s$, while $p_{0}^{\mathrm{M} *}$ is increasing in $v$ and decreasing in $s$, and $Q_{n}^{\mathrm{SR} *}$ is decreasing in $v$ and $s$. Similar to Model C, the retail price and the demand of primary consumers are independent of $v$ and $s$ and is only affected by $c_{n}$. The larger the $c_{n}$ value is, the smaller the retail price and the demand of primary consumers are. It is understandable that the forward supply chain is constant with the increase of $v$ and $s$, and a larger unit subsidy $s$ is beneficial for the manufacturer.

4.3. Single Retailer Implementing Trade-In Strategy (Model $S R$ ). The manufacturer only produces new products, single retailer (retailer 1) implements trade-in strategy and sells new products, and the other retailer (retailer 2) is only engaged in product sales. Therefore, the game order of this model is that the manufacturer first decides the wholesale price $w$, the retailer 1 determines the demand of primary consumers $q_{1 n}$ and the demand of replacement consumers $q_{1 t}$, and the retailer 2 decides the demand of primary consumers $q_{2 n}$. lows:

The retailers' objective functions can be defined as fol-

$$
\begin{aligned}
& \Pi_{R_{1}}^{\mathrm{SR}}=\max _{q_{1 n}, q_{1 t}}\left\{\left(p_{n}-w\right) q_{1 n}+\left(p_{n}-w+v-p_{0}\right) q_{1 t}\right\}, \\
& \Pi_{R_{2}}^{\mathrm{SR}}=\max _{q_{2 n}}\left(p_{n}-w\right) q_{2 n} .
\end{aligned}
$$

Given that $w$ is the decision of the manufacturer, the manufacturer's profit-maximization problem is as follows:

$$
\begin{aligned}
\Pi_{M}^{\mathrm{SR}}=\max _{w} & \left(w-c_{n}\right)\left(Q_{n}+Q_{t}\right), \\
\text { s.t. } & Q_{n}=q_{1 n}+q_{2 n} \geq 0, \\
& Q_{t}=q_{1 t} \geq 0 .
\end{aligned}
$$

Proposition 3. In Model SR, the optimal policies are as follows:

$$
\begin{aligned}
& w^{S R *}=\frac{4 \delta \alpha\left(1+c_{n}\right)+3 \beta\left(s+\delta+v+c_{n}\right)}{8 \delta \alpha+6 \beta}, \\
& q_{2 n}^{S R *}=q_{1 n}^{S R *} \\
& =\frac{4 \delta \alpha^{2}\left(1-c_{n}\right)+3 \alpha \beta\left(2-s-\delta-v-c_{n}\right)}{24 \delta \alpha+18 \beta}, \\
& Q_{t}^{S R *}=q_{1 t}^{S R *} \\
& =\frac{4 \delta \alpha \beta\left(2 s+2 \delta+2 v-c_{n}-1\right)+3 \beta^{2}\left(s+\delta+v-c_{n}\right)}{16 \delta^{2} \alpha+12 \delta \beta} .
\end{aligned}
$$

The optimal retail price and trade-in rebate can be derived as follows:

$$
\begin{aligned}
& p_{n}^{\mathrm{SR} *}=\frac{4 \delta \alpha\left(2+c_{n}\right)+3 \beta\left(1+s+\delta+v+c_{n}\right)}{12 \delta \alpha+9 \beta}, \\
& p_{0}^{\mathrm{SR} *} \\
& =\frac{4 \delta \alpha\left(c_{n}+6 v-6 s-6 \delta+5\right)+3 \beta\left(c_{n}+7 v-5 s-5 \delta+4\right)}{48 \delta \alpha+36 \beta} .
\end{aligned}
$$

By substituting the optimal prices and demands derived above into (12) and (13), we can obtain the optimal profits as follows:

$$
\begin{aligned}
& \Pi_{R_{1}}^{\mathrm{SR} *}= \frac{\alpha\left[4 \delta \alpha\left(1-c_{n}\right)+3 \beta\left(2-s-\delta-v-c_{n}\right)\right]^{2}}{(24 \delta \alpha+18 \beta)^{2}}+\frac{\beta}{\delta} \\
& \cdot \frac{\left[4 \delta \alpha\left(2 s+2 \delta+2 v-c_{n}-1\right)+3 \beta\left(s+\delta+v-c_{n}\right)\right]^{2}}{(16 \delta \alpha+12 \beta)^{2}}, \\
& \Pi_{R_{2}}^{\mathrm{SR} *}=\frac{\alpha\left[4 \delta \alpha\left(1-c_{n}\right)+3 \beta\left(2-s-\delta-v-c_{n}\right)\right]^{2}}{(24 \delta \alpha+18 \beta)^{2}}, \\
& \Pi_{M}^{\mathrm{SR} *}=\frac{\left[4 \delta \alpha\left(1-c_{n}\right)+3 \beta\left(v+\delta+s-c_{n}\right)\right]^{2}}{24\left(4 \delta^{2} \alpha+3 \delta \beta\right)} .
\end{aligned}
$$

It can be observed that $w^{\mathrm{SR} *}, p_{n}^{\mathrm{SR} *}, Q_{t}^{\mathrm{SR} *}$, and $\Pi_{M}^{\mathrm{SR} *}$ are increasing in $v$ and $s$, while $p_{0}^{\mathrm{SR} *}$ is increasing in $v$ and 
decreasing in $s$, and $Q_{n}^{\mathrm{SR} *}$ is decreasing in $v$ and $s$. The above analyses indicate that the retailer 1 would endeavor to undertake trade-in activities under the incentives with the increase of $v$ and $s$.

4.4. Two Retailers Implementing Trade-In Strategy (Model TR). Similar to the case of Model SR, the manufacturer is responsible for producing activities. Two retailers conduct product sales and trade-in activities concurrently. The game between them is Stackelberg. First, the manufacturer determines the wholesale price $w$. Second, the retailer 1 decides the demands $q_{1 n}$ and $q_{1 t}$, while the retailer 2 determines the demands $q_{2 n}$ and $q_{2 t}$. The retailers' profit functions are as follows:

$$
\begin{aligned}
& \Pi_{R_{1}}^{\mathrm{TR}}=\max _{q_{1 n}, q_{1 t}}\left\{\left(p_{n}-w\right) q_{1 n}+\left(p_{n}-w+v-p_{0}\right) q_{1 t}\right\}, \\
& \Pi_{R_{2}}^{\mathrm{TR}}=\max _{q_{2 n}, q_{2 t}}\left\{\left(p_{n}-w\right) q_{2 n}+\left(p_{n}-w+v-p_{0}\right) q_{2 t}\right\} .
\end{aligned}
$$

And the profit function of the manufacturer can be expressed as follows:

$$
\begin{aligned}
\Pi_{M}^{\mathrm{TR}}=\max _{w} & \left(w-c_{n}\right)\left(Q_{n}+Q_{t}\right), \\
\text { s.t. } & Q_{n}=q_{1 n}+q_{2 n} \geq 0, \\
& Q_{t}=q_{1 t}+q_{2 t} \geq 0 .
\end{aligned}
$$

Proposition 4. In Model TR, the optimal policies can be derived as follows:

$$
\begin{aligned}
& w^{T R *}=\frac{\delta \alpha\left(1+c_{n}\right)+\beta\left(s+\delta+v+c_{n}\right)}{2 \delta \alpha+2 \beta}, \\
& q_{2 n}^{T R *}=q_{1 n}^{T R *}=\frac{\delta \alpha^{2}\left(1-c_{n}\right)+\alpha \beta\left(2-s-\delta-v-c_{n}\right)}{6 \delta \alpha+6 \beta}, \\
& q_{2 t}^{T R *}=q_{1 t}^{T R *} \\
& =\frac{\delta \alpha \beta\left(2 v+2 \delta+2 s-c_{n}-1\right)+\beta^{2}\left(s+\delta+v-c_{n}\right)}{6 \delta^{2} \alpha+6 \delta \beta} .
\end{aligned}
$$

Furthermore, we can obtain the optimal retail price and trade-in rebate as follows:

$$
\begin{aligned}
& p_{n}^{\mathrm{TR} *}=\frac{\delta \alpha\left(2+c_{n}\right)+\beta\left(1+s+\delta+v+c_{n}\right)}{3 \delta \alpha+3 \beta}, \\
& p_{0}^{\mathrm{TR} *}=\frac{2 v-\delta-s+1}{3} .
\end{aligned}
$$

Substituting the values of the parameters into (17) and (18), we obtain the optimal profits of chain members as follows:

$$
\begin{aligned}
& \Pi_{R_{1}}^{\mathrm{TR} *}=\Pi_{R_{2}}^{\mathrm{TR} *} \\
&= \frac{\alpha\left[\delta \alpha\left(1-c_{n}\right)+\beta\left(2-s-\delta-v-c_{n}\right)\right]^{2}}{(6 \delta \alpha+6 \beta)^{2}}+\frac{\beta}{\delta} \\
& \cdot \frac{\left[\delta \alpha\left(2 v+2 \delta+2 s-c_{n}-1\right)+\beta\left(s+\delta+v-c_{n}\right)\right]^{2}}{(6 \delta \alpha+6 \beta)^{2}}, \\
& \Pi_{M}^{\mathrm{TR} *}=\frac{\left[\delta \alpha\left(1-c_{n}\right)+\beta\left(v+\delta+s-c_{n}\right)\right]^{2}}{6\left(\delta^{2} \alpha+\delta \beta\right)} .
\end{aligned}
$$

Most insights of Model TR are similar to Model SR; the wholesale price $w^{\mathrm{TR} *}$, the retail price $p_{n}^{\mathrm{TR} *}$, the demand of trade-in consumers $Q_{t}^{\mathrm{TR} *}$, and the manufacturer's profit $\Pi_{M}^{\mathrm{TR} *}$ are increasing in $v$ and $s$; the trade-in rebate $b^{\mathrm{TR} *}$ is increasing in $v$ and decreasing in $s ; Q_{t}^{\mathrm{TR} *}$ is decreasing in $v$ and $s$. In addition, the competition between two retailers in the forward and reverse flows becomes more intense with the increase of $v$ and $s$.

\section{Comparative Analyses}

In this section, we compare the four CLSC models with respect to the prices, demands, and profits and find some analytical results and interesting observations.

Corollary 5. The optimal retail price and wholesale price are related as follows:

1. If $b>1-\delta$, then $w^{M *}<w^{S R *}<w^{T R *}, p_{n}^{C *}<p_{n}^{M *}<$ $p_{n}^{S R *}<p_{n}^{T R *}$.

2. If $\left(1+c_{n}\right) / 2-\delta \alpha\left(1-c_{n}\right) / 2 \beta-\delta<b<1-\delta$, then $w^{T R *}<w^{S R *}<w^{M *}, p_{n}^{C *}<p_{n}^{T R *}<p_{n}^{S R *}<p_{n}^{M *}$.

3. If $\left(1+c_{n}\right) / 2-2 \delta \alpha\left(1-c_{n}\right) / 3 \beta-\delta<b<\left(1+c_{n}\right) / 2-\delta \alpha(1-$ $\left.c_{n}\right) / 2 \beta-\delta$, then one can get $w^{T R *}<w^{S R *}<w^{M *}$ and $p_{n}^{T R *}<p_{n}^{C *}<p_{n}^{S R *}<p_{n}^{M *}$.

4. If $b<\left(1+c_{n}\right) / 2-2 \delta \alpha\left(1-c_{n}\right) / 3 \beta-\delta$, then $w^{T R *}<$ $w^{S R *}<w^{M *}, p_{n}^{T R *}<p_{n}^{S R *}<p_{n}^{C *}<p_{n}^{M *}$.

Corollary 5 indicates the ranks of the wholesale price and the retail price of each model with different strategy space of $b$. The manufacturer, as the channel leader, would set the wholesale price according to different trade-in schemes and entice to increase the profit of the manufacturer and the whole supply chain. When the net value of used products is large enough (i.e., $b>1-\delta$ ), the wholesale price in Model $\mathrm{M}$ is lower than that in Model SR and Model TR, and the wholesale price in Model TR is the largest. This phenomenon can be explained by the fact that the manufacturer would reduce the wholesale price to extend the scale of reverse supply chain and accordingly obtain more profits from tradein activities when he is engaged in collecting activities. 
Differently, when the manufacturer does not undertake the collection of used products, the manufacturer would rise his wholesale price to obtain more revenues from the forward flow in both Model SR and Model TR. Comparing the wholesale price in Model SR and Model TR, if the unit profit from trade-in strategy is sufficiently high, as there exists retailers' competition on both new product sales and trade-in activities in Model TR, the competition between two retailers in Model TR is more intense than that in Model SR, and eventually the manufacturer would benefit from the retailers' competition. Moreover, the retail price is directly dependent on the wholesale price. While the unit profit from trade-in strategy is relatively small (i.e., $b<1-\delta$ ), the optimal retail price in Model SR is located between that in Model TR and that in Model SR; namely, $p_{n}^{\mathrm{TR} *}<p_{n}^{\mathrm{SR} *}<p_{n}^{\mathrm{M} *}$. The retail price in Model $C$ is a fixed value and has no relationship with the net value $b$, and the rank of $p_{n}^{\mathrm{TR} *}, p_{n}^{\mathrm{SR} *}$, and $p_{n}^{\mathrm{M} *}$ will change with various $b$.

Corollary 6. The optimal demand of primary consumers satisfies the relations as follows:

$$
\begin{aligned}
& \text { 1. If } b \in(1-\delta, 2) \text {, then } Q_{n}^{C *}>Q_{n}^{M *}>Q_{n}^{S R *}>Q_{n}^{T R *} \text {. } \\
& \text { 2. If } b \in\left(\left(1+c_{n}\right) / 2-\delta \alpha\left(1-c_{n}\right) / 2 \beta-\delta, 1-\delta\right) \text {, then } \\
& Q_{n}^{C *}>Q_{n}^{T R *}>Q_{n}^{S R *}>Q_{n}^{M *} \text {. } \\
& \text { 3. If } b \in\left(\left(1+c_{n}\right) / 2-2 \delta \alpha\left(1-c_{n}\right) / 3 \beta-\delta,\left(1+c_{n}\right) / 2-\right. \\
& \left.\delta \alpha\left(1-c_{n}\right) / 2 \beta-\delta\right) \text {, then } Q_{n}^{T R *}>Q_{n}^{C *}>Q_{n}^{S R *}>Q_{n}^{M *} \text {. } \\
& \text { 4. If } b \in\left(0,\left(1+c_{n}\right) / 2-2 \delta \alpha\left(1-c_{n}\right) / 3 \beta-\delta\right) \text {, then } Q_{n}^{T R *}> \\
& Q_{n}^{C *}>Q_{n}^{S R *}>Q_{n}^{M *} \text {. }
\end{aligned}
$$

Subsequently, Corollary 6 analytically reveals the change of the demand of primary consumers $Q_{n}$ with different strategy space of $b$. When the net value of used products $(b)$ is relatively large, the demand in the centralized model is larger than that in the decentralized models, which is presented in Corollary 6(1) and (2). It is found that, if the unit profit from trade-in is relatively small (i.e., $b<1-\delta$ ), the demand of primary consumers in Model $\mathrm{M}$ would be the smallest. This implies that a lower net value of used products weakens the incentive of the manufacturer undertaking trade-in activities. It should be noted that, in Model M, the retailers only sell new products and have no control over the collection of used products, and they would increase the retail price with an increase of $w$. As a result, the demand of primary consumers becomes smaller in Model M. Besides, when the net value of used products $(b)$ is sufficiently small, the demand of primary consumers can be the largest, because the decrease of $b$ will ease the competition between two retailers in Model TR, which is presented in Corollary 6(3) and (4).

Corollary 7. The optimal demand of trade-in consumers satisfies the following relationships:

1. In the case of $\delta \alpha<\beta$ (i.e., $\beta /(\alpha+\beta)>\delta /(1+\delta)$ ), then $Q_{t}^{C *}=Q_{t}^{M *}>Q_{t}^{T R *}>Q_{t}^{S R *}$.

2. In the case of $\delta \alpha>\beta$ (i.e., $\beta /(\alpha+\beta)<\delta /(1+\delta)$ ), if $b>(2 \delta \alpha /(\delta \alpha-\beta))+c_{n}-\delta$, then one can get that $Q_{t}^{T R *}>$
$Q_{t}^{M *}=Q_{t}^{C *}>Q_{t}^{S R *}$; else if $b<2 \delta \alpha /(\delta \alpha-\beta)+c_{n}-\delta$, then one can get that $Q_{t}^{C *}=Q_{t}^{M *}>Q_{t}^{T R *}>Q_{t}^{S R *}$.

From Corollary 7, we can observe that the demand of trade-in consumers in Model C is equivalent to that in Model $\mathrm{M}$. Considering single chain member (the manufacturer/the retailer) implementing trade-in strategy in Model $M$ and Model SR, the demand in Model M is larger than that in Model SR, and the demand in Model TR is larger than that in Model SR. The relationship of the demand in Model $\mathrm{M}$ and Model TR depends on the proportion of trade-in consumers (i.e., $\beta /(\alpha+\beta))$. If the proportion of trade-in consumers is beyond a critical value (i.e., $\delta /(1+\delta)$ ), larger demand can be achieved in Model $M$ than that in Model TR. On the contrary, the retailers would spare no effort to implement trade-in strategy; thereby a larger demand in Model TR than that in Model $\mathrm{M}$ will be achieved only if the proportion of trade-in consumers is less than a boundary value and $b>$ $\left(2 \delta \alpha-(\delta \alpha+\beta) c_{n}\right) /(\delta \alpha-\beta)-\delta$ also holds. Based on the above analyses, we can draw the conclusion that both Model $M$ and Model TR are more beneficial for the environment than Model SR, and Model C and Model M are identical from the view of environment performance.

Corollary 8. The comparisons of the optimal trade-in rebate are as follows:

$$
\begin{aligned}
& \text { 1. If } b \in\left(2-c_{n}-\delta, 2\right) \text {, then } p_{0}^{S R *}<p_{0}^{C *}<p_{0}^{M *}<p_{0}^{T R *} \text {. } \\
& \text { 2. If } b \in\left(1-\delta, 2-c_{n}-\delta\right) \text {, then } p_{0}^{S R *}<p_{0}^{C *}<p_{0}^{T R *}<p_{0}^{M *} \text {. } \\
& \text { 3. If } b \in(0,1-\delta) \text {, then } p_{0}^{S R *}<p_{0}^{T R *}<p_{0}^{C *}<p_{0}^{M *} \text {. }
\end{aligned}
$$

Corollary 8 describes the order of the trade-in rebate $p_{0}$ in each model with the various net values of a used product $b$. No matter what the strategy space of $b$ is, the trade-in rebate in Model SR is definitely the smallest, because the single retailer in Model SR has no incentive to increase the trade-in rebate when there is no competition on trade-in activities. Additionally, with the increase of the net value $b$, the competition between two retailers in Model TS becomes more and more intense. When $b$ exceeds the critical value (i.e., $2-c_{n}-\delta$ ), the trade-in rebate in Model TR becomes the largest, which is indicated from Corollary 8(1). While if $b \in$ $(0,1-\delta)$, the trade-in rebate in Model TR is smaller than that in Model $\mathrm{C}$ and Model $\mathrm{M}$ because the retailers are unwilling to be engaged in trade-in activities due to relatively low net value of a used product. In addition, the manufacturer, as the channel leader, would always make no effort to implement trade-in strategy to obtain more profits. Therefore, comparing with other models, the trade-in rebate in Model M is relatively large in the whole supply chain.

Corollary 9. The optimal manufacturer's profit satisfies the following relationships:

$$
\begin{aligned}
& \text { 1. } \Pi_{M}^{S R *}<\Pi_{M}^{M *} \text { and } \Pi_{M}^{T R *}<\Pi_{M}^{M *} \text {. } \\
& \text { 2. If } b>c_{n}+4 \delta \alpha\left(1-c_{n}\right)[\sqrt{(4 \delta \alpha+3 \beta)(\delta \alpha+\beta)}- \\
& 2 \delta \alpha] / 2\left(7 \delta \alpha \beta+3 \beta^{2}\right)-\delta \text {, then } \Pi_{M}^{S R *}<\Pi_{M}^{T R *} \text {. }
\end{aligned}
$$


Corollary 9 shows two basic insights: (1) the profit obtained by the manufacturer under Model $\mathrm{M}$ is more than that under Model SR and Model TR. As for the manufacturer, he has direct control over trade-in activities in Model $\mathrm{M}$ and can obtain dual revenues from both the forward and reserve flows. (2) When the net value of used products is relatively large (i.e., $b>c_{n}+4 \delta \alpha\left(1-c_{n}\right)[\sqrt{(4 \delta \alpha+3 \beta)(\delta \alpha+\beta)}-$ $\left.2 \delta \alpha] / 2\left(7 \delta \alpha \beta+3 \beta^{2}\right)-\delta\right)$, the competition between two retailers in Model TR would be more intensive as they simultaneously undertake selling and trade-in activities. In this case, the manufacturer would also share some profits because of increased market demand. From the economic performance, there is no doubt that the centralized decision model (Model C) performs better than the manufacturer trade-in model regarding the profit of the whole supply chain.

Corollary 10. The optimal retailers' profits satisfy the relations as follows:

$$
\begin{aligned}
& \text { If } b>1-\delta \text {, then } \Pi_{R_{2}}^{S R *}<\Pi_{R_{1}}^{M *}=\Pi_{R_{2}}^{M *} \text { and } \Pi_{R_{1}}^{T R *}= \\
& \Pi_{R_{2}}^{T R *}<\Pi_{R_{1}}^{S R *} .
\end{aligned}
$$

Assuming that the net value of a used product is relatively large (i.e., $b>1-\delta$ ), the case where the trade-in strategy is implemented by the manufacturer dominates the case where the trade-in strategy is implemented by the other retailer for the retailer who only undertakes selling products. This is due to the fact that the manufacturer, who acts as the channel leader, can make a balance between the sales of new products and the collection of used products. Additionally, according to Corollary 5, since the manufacturer extends the scale of the forward supply chain by setting a lower wholesale price in Model M, the wholesale price in Model M is lower than that in Model SR. As a result, the retailer can sell more products and earn more profits in Model $M$ than that in Model SR. On the other hand, if trade-in strategy is profitable (i.e., $b>1-\delta$ ), the retailer who is engaged in trade-in activities can obtain more profits in Model SR than that in Model TR due to the more intense competition between two retailers in Model TR.

Corollary 11. (1) The net utility of primary consumers satisfies the following relationships: If $b>1-\delta$, then $U_{n}^{C *}>U_{n}^{M *}>$ $U_{n}^{S R *}>U_{n}^{T R *}$.

(2) The net utility of trade-in consumers satisfies the following relationships:

1. When $\delta \alpha<\beta$ (i.e., $\beta /(\alpha+\beta)>\delta /(1+\delta)$ ), then $U_{t}^{C *}=$ $U_{t}^{M *}>U_{t}^{T R *}>U_{t}^{S R *}$.

2. When $\delta \alpha>\beta$ (i.e., $\beta /(\alpha+\beta)<\delta /(1+\delta)$ ), if $b>$ $2 \delta \alpha /(\delta \alpha-\beta)+c_{n}-\delta$, then $U_{t}^{T R *}>U_{t}^{M *}=U_{t}^{C *}>U_{t}^{S R *}$; else if $b<2 \delta \alpha /(\delta \alpha-\beta)+c_{n}-\delta$, then $U_{t}^{C *}=U_{t}^{M *}>$ $U_{t}^{T R *}>U_{t}^{S R *}$.

We consider the influence of the net value of a used product $b$ on the net utilities of primary consumers and replacement consumers. For one thing, as $U_{n}=\theta-p_{n}$ holds, there is inverse relationship between $p_{n}$ and $U_{n}$, and thus primary consumers can generally get a higher utility with a lower $p_{n}$. Based on Corollary 5 , if the net value $b$ exceeds a threshold value (i.e., $b>1-\delta$ ), the net utility of primary consumers in Model $\mathrm{C}$ is the largest, and the net utility of primary consumers in Model $\mathrm{M}$ is larger than that in both Model SR and Model TR. For another thing, as the net utility of trade-in consumers satisfies $U_{t}=\theta-\delta+\delta Q_{t} / \beta$, the net utility $U_{t}$ is proportional to the demand of replacement consumers $Q_{t}$. This implies that a larger $Q_{t}$ leads to a larger utility $U_{t}$ for the replacement consumers. We can acquire Corollary 11(2) from Corollary 7.

\section{Numerical Examples}

In this section, we provide a detailed comparison of the corresponding results in the centralized model and three decentralized models and study the change trend of the optimal wholesale price, the retail price, the demands of primary consumers and replacement consumers, and the chain members' profits with respect to the net value of a used product. Moreover, we analyze the effect of different tradein schemes on the scale of supply chain and environmental performance. We assume that $\alpha=\beta=100, c_{n}=0.4$, and $\delta=0.3$.

We demonstrate the impact of the net value of a used product $b$ on the wholesale price $w$ and the retail price $p_{n}$. As depicted in Figure 2, the wholesale price in Model $\mathrm{M}$ and the retail price in Model C and Model M have no relationship with the net value, and the wholesale price and the retail price in Model SR and Model TR are increasing in $b$. Consistent with Corollary 5 , if the net profit from trade-in activities is high enough (i.e., $b>1-\delta$ ), the wholesale price and the retail price under Model TR are larger than those under Model SR. It can be understood that, if the trade-in strategy is profitable, the competition between two retailers is more intense with the increase of $b$, and the manufacturer and the retailers can share the profits from trade-in activities by increasing the wholesale price and the retail price, respectively.

Figure 3 shows the evolution of the demand of primary consumers on four-strategy space of the net value $b$. It can be observed that the demand of primary consumers in Model SR and that in Model TR are decreasing with the increase of $b$. Assuming that the retail price is increasing, the consumers is unwilling to purchase new products, and eventually the scale of the forward distribution channels would gradually shrink. Under Model SR and Model TR, the net value of a used product has a negative impact on the demand of primary consumers. Specifically, when trade-in strategy is more significant with the increase of $b$, the retailers have no incentive to reduce the retail price to increase demand, because they can obtain more profits from trade-in activities in the reverse flow.

Figures 4(a) and 4(b) illustrate that no matter what the rate of replacement consumers is, the demand of replacement consumers increases in the net value of a used product $b$, and the net value has a positive effect on the trade-in strategy. Specifically, the demand of replacement consumers in Model $\mathrm{M}$ is the same as that in Model C. Moreover, when the trade-in strategy is profitable with the increase of $b$, the manufacturer 


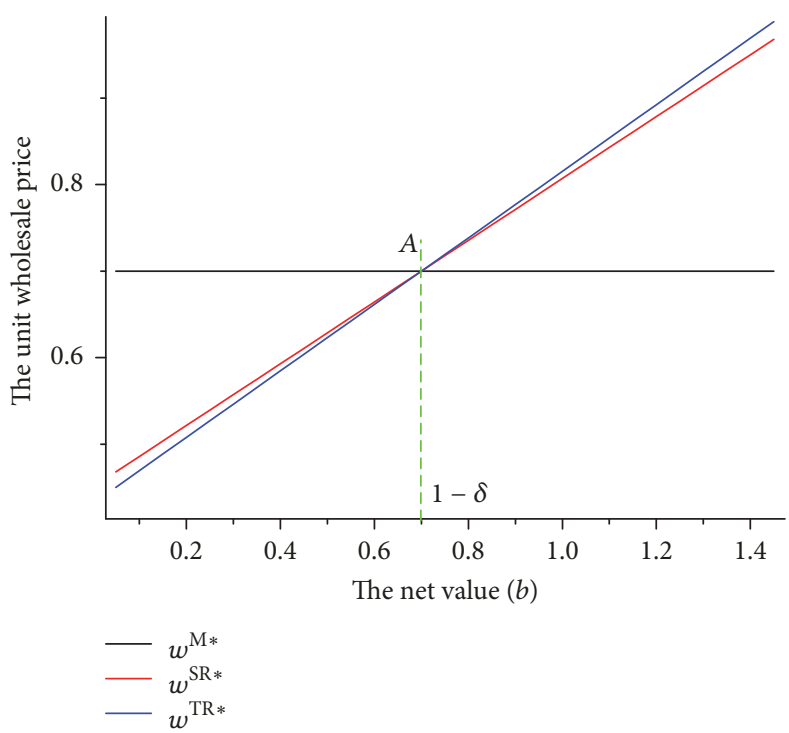

(a)

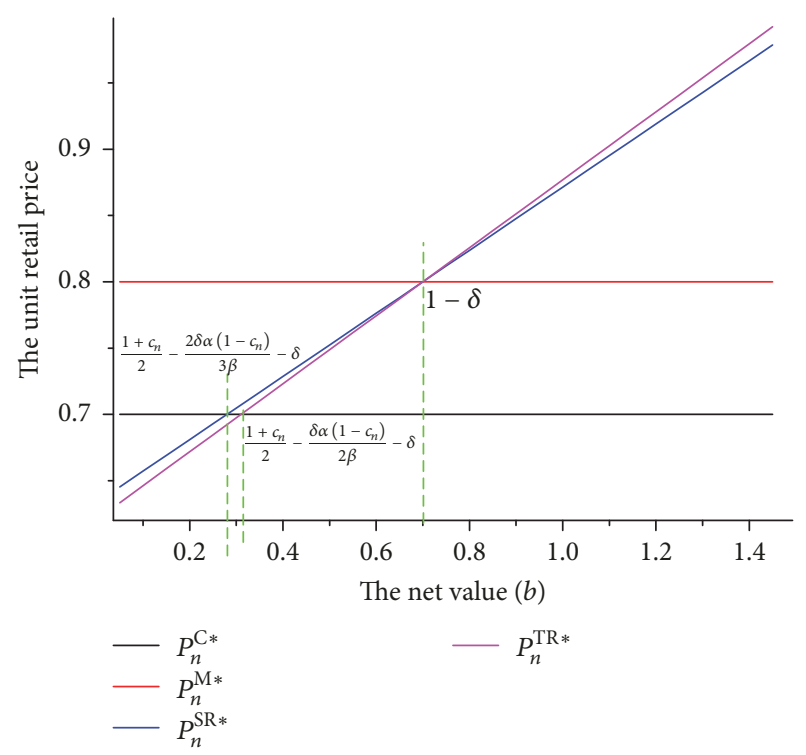

(b)

Figure 2: (a) The wholesale price versus the net value of a used product, (b) the retail price versus the net value of a used product.

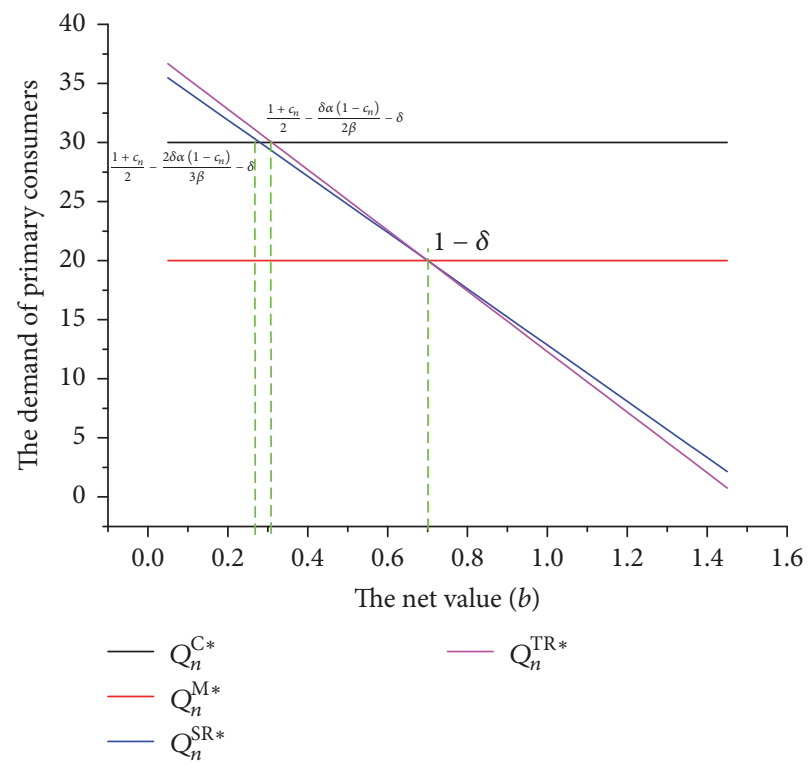

FIGURE 3: The demand of primary consumers versus the net value of a used product.

and the retailers have the incentive to implement trade-in strategy to obtain more profits. In this case, trade-in strategy can create real value in the case where the net value $b$ is high enough. As a result, the scale of the reverse supply chain becomes larger and the trade-in activities would improve the environmental performance.

As clearly shown in Figure 5, the higher $v$ leads to the larger trade-in rebate in each model, and the influence of $s$ is opposite to that of $v$. On the one hand, since the net value of a used product $b$ increases with the increase of $v$, the chain members can obtain more profits by implementing trade-in strategy. As a response, the manufacturer and the retailers would increase the trade-in rebate and eventually acquire more profits from trade-in activities. On the other hand, when the government elevates the subsidy $s$, it is profitable for chain members to undertake trade-in activities in a lower trade-in rebate. The government subsidy splays a significant role in determining the value of trade-in rebate. Specifically, the trade-in rebate decreases dramatically with increasing $s$.

Figure 6 reveals that the manufacturer's profit increases with the increase of $b$ in Model M, Model SR, and Model TR. It can be observed that the manufacturer's profit in Model $\mathrm{M}$ is the largest and the slope coefficient of the curve of $\Pi_{M}^{\mathrm{M} *}$ under Model $\mathrm{M}$ is the largest, which shows that the 


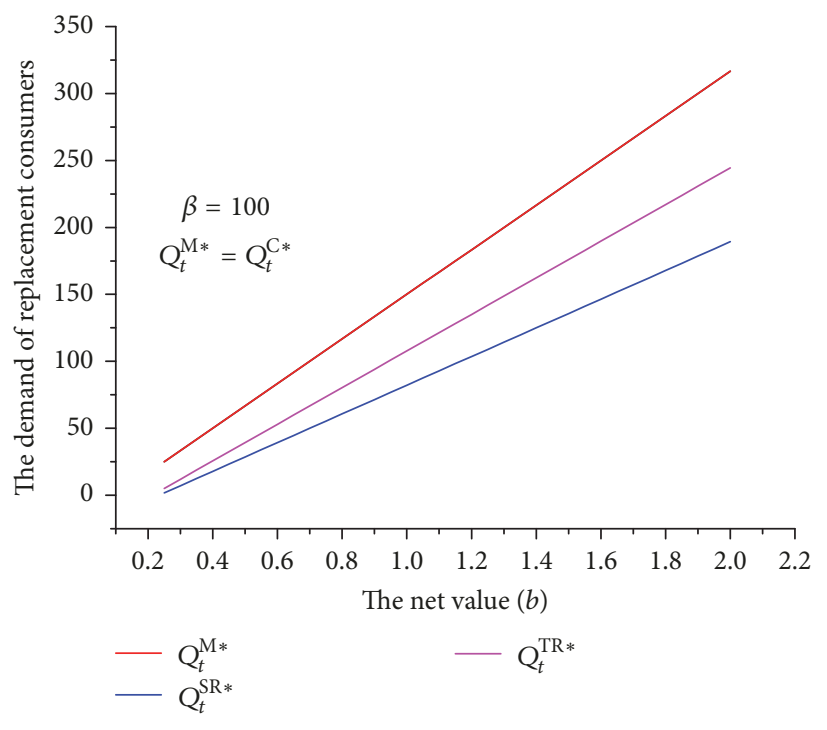

(a)

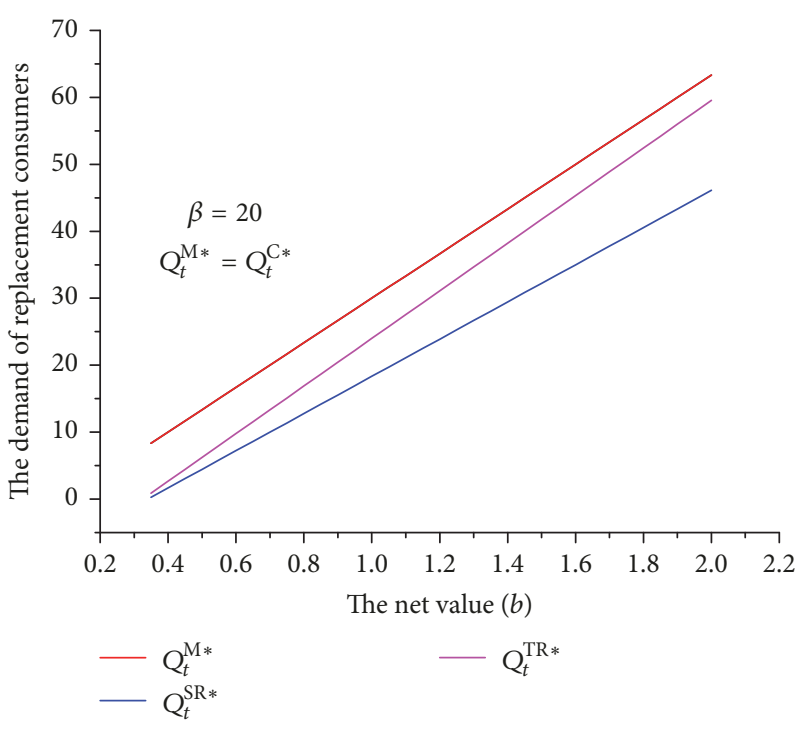

(b)

Figure 4: The demand of replacement consumers versus the net value of a used product with (a) $\beta=100$ and (b) $\beta=20$.

manufacturer's profit under Model $M$ increases rapidly. It should also be noted that the manufacturer's profit in Model TR is larger than that in Model SR when $b$ is beyond a threshold (i.e., B). It can be explained that the manufacturer not only undertakes producing activities, but also implements trade-in strategy, which suggests that the manufacturer can acquire double revenues. As a higher $b$ induces a higher profit for the manufacturer, the manufacturer would endeavor to collect more used products and eventually earn more profits. Additionally, the manufacturer could share more profits from trade-in strategy by increasing the wholesale price $w$, when the competition between two retailers in Model TR is more intense with the increase of $b$. It can be concluded that tradein strategy can always boost the manufacturer's profit in each model.

We turn to the examination of the retailers' profits. As depicted from Figure 7, the profits of the retailer 1 in Model SR and Model TR increase with the increase of $b$. And the profit of retailer 1 in Model SR is the largest, and the rising slope of $\Pi_{R_{1}}^{\mathrm{SR} *}$ is also the largest. It can be explained that the retailer 1 can always obtain profits from trade-in strategy. Moreover, as there is no competition in trade-in activities under Model SR, the retailer 1 can obtain maximum profit among all models. As for the retailer 2, the trends of the profits of the retailer 2 in Model M and Model SR are flat, which suggests that trade-in strategy plays a relatively weaker role in the profits of the retailer 2 when he does not undertake trade-in activities. Additionally, the profit of the retailer 2 in Model M is larger than that in Model SR when the net value $b$ exceeds the threshold (i.e., point $C$ ), because the manufacturer can better coordinate the forward and reverse flows.

It can also be concluded that the retailers who undertake trade-in activities can acquire more profits with the increase of $b$ in both Model SR and Model TR. However, the retailers' profits are relatively small when they only undertake marketing products. If the net value $b$ is relatively large, Model $\mathrm{M}$ is more profitable for the retailer who only conducts the sales of products, which is consistent with Corollary 10. The manufacturer, as the channel leader, can make a balance between the forward and reverse flows, and eventually the retailer sets the optimal pricing decisions based on the manufacturer's strategies in Model M.

\section{Conclusions and Future Research}

This paper develops a CLSC comprising one manufacturer and two retailers, in which one manufacturer, single retailer, and two retailers implement trade-in strategy, respectively. We acquire and compare the equilibrium decisions of the centralized model and three decentralized models and explore the impact of the net value of a used product on chain members and environmental performance. Our research could offer some guidelines on how to improve supply chain performance by choosing different trade-in strategies under retailers' competition.

Our results offer several insights. First, the manufacturer achieves the maximum profit in Model M. We show that, if the net profit of a used product is high enough, the manufacturer's profit in Model TR is larger than that in Model SR, because the manufacturer could benefit from the intense competition between two retailers in Model TR. As for the retailers, if $b>1-\delta$ holds, Model SR dominates Model TR for the retailer who only undertakes product sales. And Model M dominates Model SR for the retailer who conducts both product sales and trade-in activities. Second, from the perspective of consumers, trade-in activities are attractive if the net value of a used product is sufficiently large; the primary consumers can obtain the largest net utility in the centralized model and prefer to implement trade-in 

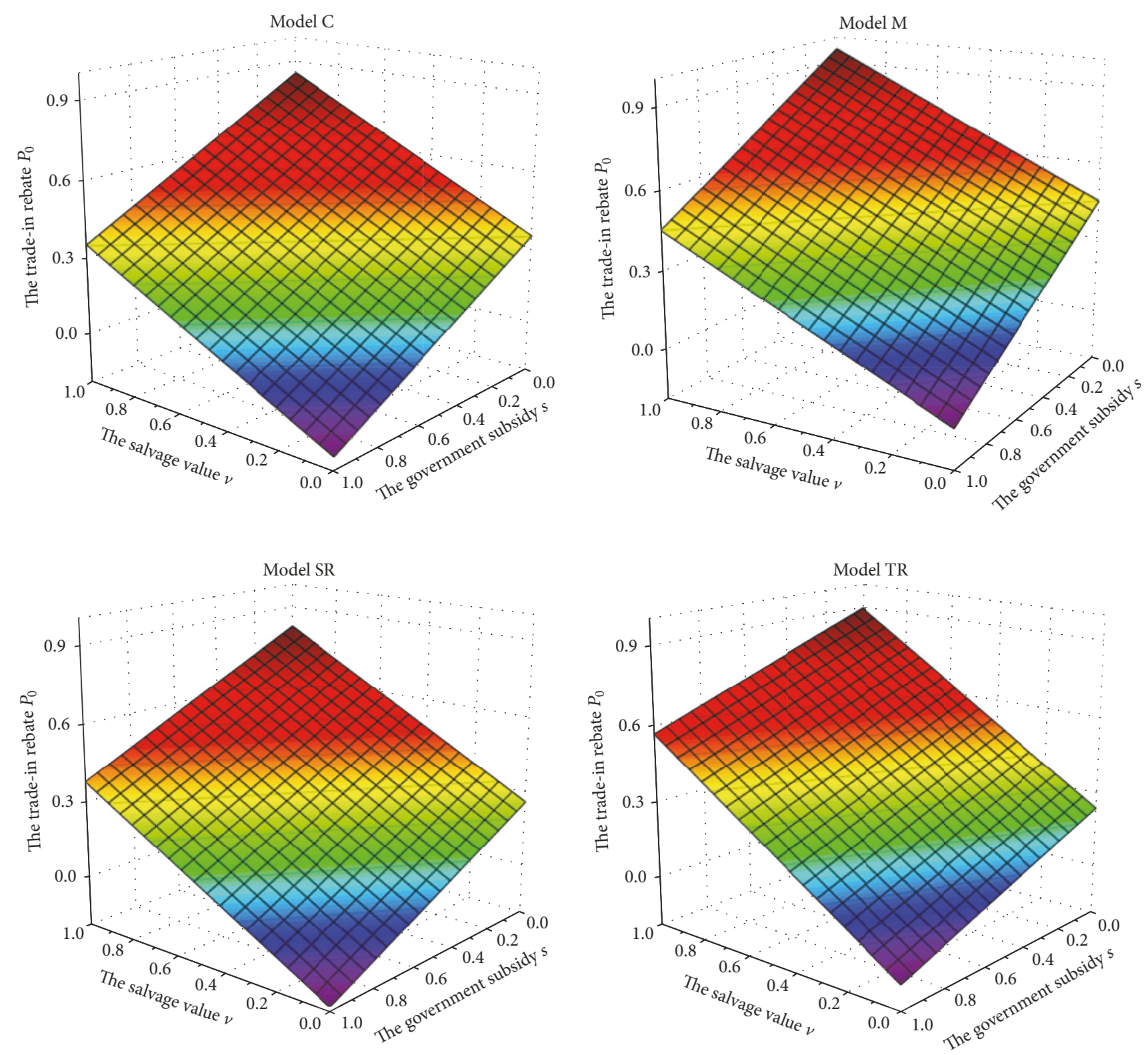

Figure 5: Changes in $P_{0}$ with $v$ and $s$.

strategy by the manufacturer rather than that by the retailers, while for the replacement consumers, Model C and Model M contribute the same net utility and Model SR furnishes the least net utility among all the models.

Furthermore, the net value of a used product $b$ would also affect the scale of the whole supply chain. When the net value of a used product exceeds the critical value, the demand of primary consumers in Model C is the largest. Since the manufacturer can coordinate the forward and reverse flows in Model M, the demand in Model M is larger than that in Model SR and Model TR. Since the scale of the reverse supply chain has a positive effect on environmental performance, Model $\mathrm{M}$ and Model $\mathrm{C}$ make the equal contributions to the environment, and the cases where the manufacturer and two retailers implement trade-in strategy are more beneficial for the environment than the case of single retailer undertaking trade-in activities. Meanwhile, the contribution degree of Model M and Model TR depends on the net value of a used product. Specifically, if the net value of a used product is relatively large, Model TR has an advantage over Model M for the environmental performance.

Finally, some research directions deserve investigation to further expand our models. We focus on the scenario where two retailers are engaged in the trade-in activities. However, it is more realistic to examine the scene with multiple competing retailers in a CLSC. Moreover, a multiperiod model rather than a single-period model is also needed to effectively analyze trade-in strategies. 


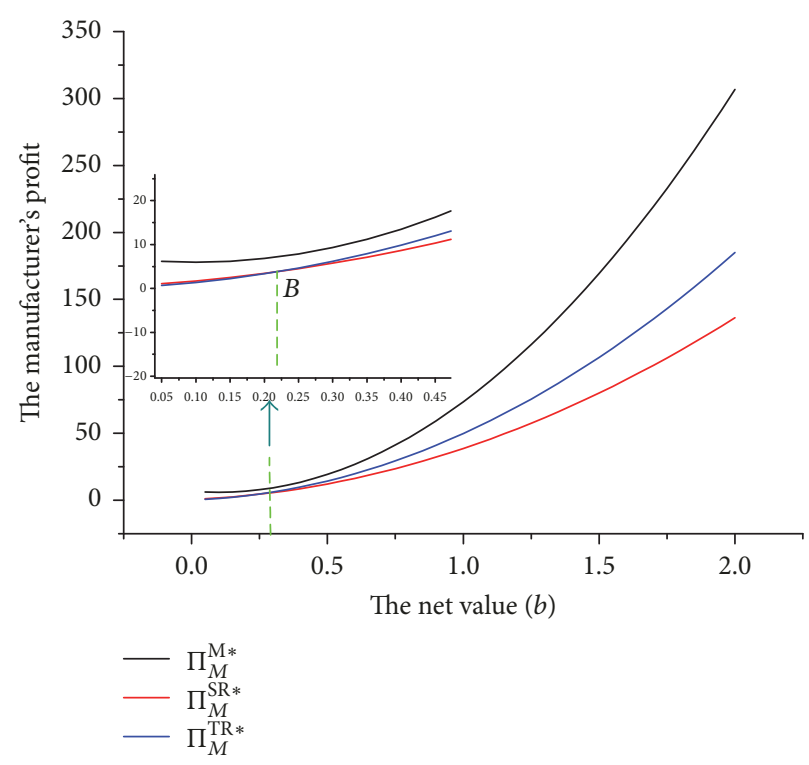

FIGURE 6: The manufacturer's profit versus the net value of a used product.

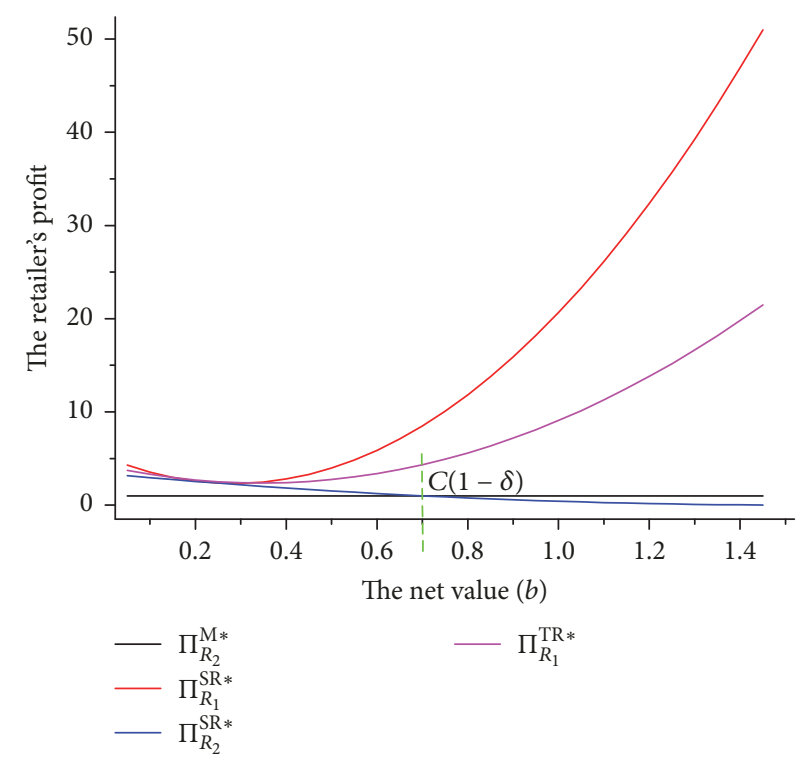

FIgURE 7: The retailer's profit versus the net value of a used product.

\section{Appendix}

Proof of Proposition 1. The Hessian matrix of $\Pi^{\mathrm{C}}$ with respect to $Q_{n}$ and $Q_{t}$ is

$$
H^{\mathrm{C}}=\left(\begin{array}{cc}
\frac{\partial^{2} \Pi^{\mathrm{C}}}{\partial Q_{n}{ }^{2}} & \frac{\partial^{2} \Pi^{\mathrm{C}}}{\partial Q_{n} \partial Q_{t}} \\
\frac{\partial^{2} \Pi^{\mathrm{C}}}{\partial Q_{t} \partial Q_{n}} & \frac{\partial^{2} \Pi^{\mathrm{C}}}{\partial Q_{t}{ }^{2}}
\end{array}\right)=\left(\begin{array}{cc}
-\frac{2}{\alpha} & 0 \\
0 & -\frac{2 \delta}{\beta}
\end{array}\right) .
$$

Since $\partial^{2} \Pi^{\mathrm{C}} / \partial Q_{n}{ }^{2}=-2 / \alpha<0$ and $\left|H^{\mathrm{C}}\right|=4 \delta / \alpha \beta>0, \Pi^{\mathrm{C}}$ is jointly concave in $Q_{n}$ and $Q_{t}$. The optimal price strategy can be solved as follows:

$$
\begin{aligned}
& \frac{\partial \Pi^{\mathrm{C}}}{\partial Q_{n}}=1-c_{n}-\frac{2 Q_{n}}{\alpha}=0 \\
& \frac{\partial \Pi^{\mathrm{C}}}{\partial Q_{t}}=s+\delta+v-c_{n}-\frac{2 \delta Q_{t}}{\beta}=0 .
\end{aligned}
$$

Proof of Proposition 2. Taking the second-order derivatives of $\Pi_{R_{1}}^{\mathrm{M}}$ and $\Pi_{R_{2}}^{\mathrm{M}}$ with respect to $q_{1 n}$ and $q_{2 n}$, respectively, we can obtain $\partial^{2} \Pi_{R_{1}}^{\mathrm{M}} / \partial q_{1 n}{ }^{2}=-2 / \alpha<0$ and $\partial^{2} \Pi_{R_{2}}^{\mathrm{M}} / \partial q_{2 n}{ }^{2}=-2 / \alpha<$ 0 ; thus $\Pi_{R_{1}}^{\mathrm{M}}$ is concave in $q_{1 n}$ and $\Pi_{R_{2}}^{\mathrm{M}}$ is concave in $q_{2 n}$. 

follows:

Therefore, the optimal price strategy can be solved as

$$
\frac{\partial \Pi_{R_{1}}^{\mathrm{M}}}{\partial q_{1 n}}=1-w-\frac{2 q_{1 n}}{\alpha}-\frac{q_{2 n}}{\alpha}=0,
$$

$$
\frac{\partial \Pi_{R_{2}}^{\mathrm{M}}}{\partial q_{2 n}}=1-w-\frac{2 q_{2 n}}{\alpha}-\frac{q_{1 n}}{\alpha}=0 .
$$

Subsequently, the optimal problem can be transformed into:

$$
\begin{aligned}
\Pi_{M}^{\mathrm{M} *}=\max _{w, Q_{t}, p_{0}} & \left\{\left(w-c_{n}\right) \frac{2 \alpha(1-w)}{3}+\left(p_{t}-c_{n}+v-1+s+\delta+\frac{Q_{n}}{\alpha}-\frac{\delta}{\beta} Q_{t}\right) Q_{t}\right\} . \\
\text { s.t. } \quad & w \leq p_{t} \leq p_{n}
\end{aligned}
$$

And its Kuhn-Tucker conditions are

$$
\begin{aligned}
\frac{2 \alpha(1-w)}{3}-\frac{2 \alpha}{3}\left(w-c_{n}\right)-\frac{2}{3} Q_{t}+\frac{2}{3} \lambda_{1}-w & =0, \\
p_{t}-c_{n}+v+s+\delta-\frac{1+2 w}{3}-\frac{2 \delta}{\beta} Q_{t} & =0, \\
Q_{t}-\lambda_{1}+\lambda_{2} & =0, \\
\lambda_{1}\left(\frac{1+2 w}{3}-p_{t}\right) & =0, \\
\lambda_{2}\left(p_{t}-w\right) & =0, \\
\lambda_{1} & \geq 0, \\
\lambda_{2} & \geq 0 .
\end{aligned}
$$

Thus, we get the following:

1. When $\lambda_{1} \neq 0, \lambda_{2}=0$, we get

$$
\begin{aligned}
w^{\mathrm{M} *} & =\frac{1+c_{n}}{2}, \\
Q_{t}^{\mathrm{M} *} & =\frac{\beta\left(v+\delta+s-c_{n}\right)}{2 \delta}, \\
p_{t}^{\mathrm{M} *} & =p_{n}^{M *}=\frac{2+c_{n}}{3} .
\end{aligned}
$$

2. When $\lambda_{1} \neq 0, \lambda_{2} \neq 0$, there is no solution.

3. When $\lambda_{1}=0$, there is no solution.

Proof of Proposition 3. Taking the second-order partial derivatives of $\Pi_{R_{1}}^{\text {SR }}$ with respect to $q_{1 n}$ and $q_{1 t}$, we have the Hessian matrix:

$$
\begin{aligned}
H_{R_{1}}^{\mathrm{SR}} & =\left(\begin{array}{cc}
\frac{\partial^{2} \Pi_{R_{1}}^{\mathrm{SR}}}{\partial q_{1 n}^{2}} & \frac{\partial^{2} \Pi_{R_{1}}^{\mathrm{SR}}}{\partial q_{1 n} \partial q_{1 t}} \\
\frac{\partial^{2} \Pi_{R_{1}}^{\mathrm{SR}}}{\partial q_{1 t} \partial q_{1 n}} & \frac{\partial^{2} \Pi_{R_{1}}^{\mathrm{SR}}}{\partial q_{1 t}^{2}}
\end{array}\right) \\
& =\left(\begin{array}{cc}
-\frac{2}{\alpha} & 0 \\
0 & -\frac{2 \delta}{\beta}
\end{array}\right)
\end{aligned}
$$

We find that $\Pi_{R_{1}}^{\text {SR }}$ is strictly concave in $q_{1 n}$ and $q_{11}$. Taking the first-order partial derivative of $\Pi_{R_{1}}^{\mathrm{SR}}$ with respect to $q_{1 n}$ and $q_{1 t}$ and letting the derivative be zero, we have

$$
\begin{aligned}
& \frac{\partial \Pi_{R_{1}}^{\mathrm{SR}}}{\partial q_{1 n}}=1-w-\frac{2 q_{1 n}}{\alpha}-\frac{q_{2 n}}{\alpha}=0 \\
& \frac{\partial \Pi_{R_{1}}^{\mathrm{SR}}}{\partial q_{1 t}}=s+\delta-w+v-\frac{2 \delta q_{1 t}}{\beta}-\frac{\delta q_{2 t}}{\beta}=0 .
\end{aligned}
$$

Then, taking the second-order derivative of $\Pi_{R_{2}}^{\mathrm{SR}}$ with respect to $q_{2 n}$, we can obtain $\partial^{2} \Pi_{R_{2}}^{S R} / \partial q_{2 n}{ }^{2}=-2 / \alpha<0$; thus $\Pi_{R_{2}}^{\mathrm{SR}}$ is concave in $q_{2 n}$.

And the optimal price strategy can be solved as follows:

$$
\frac{\partial \Pi_{R_{2}}^{\mathrm{SR}}}{\partial q_{2 n}}=1-w-\frac{2 q_{2 n}}{\alpha}-\frac{q_{1 n}}{\alpha}=0 .
$$

Subsequently, taking the second-order derivative of $\Pi_{M}^{S R}$ with respect to $w$, we can obtain $\partial^{2} \Pi_{M}^{\mathrm{SR}} / \partial w^{2}=-4 \alpha / 3-\beta / \delta<$ 0 ; thus $\Pi_{M}^{\mathrm{SR}}$ is concave in $w$. The optimal price strategy can be solved as

$$
\begin{gathered}
\frac{\partial \Pi_{M}^{\mathrm{SR}}}{\partial w}=\frac{2 \alpha(1-w)}{3}+\frac{\beta(s+\delta+v-w)}{2 \delta} \\
-\left(\frac{2 \alpha}{3}+\frac{\beta}{2 \delta}\right)\left(w-c_{n}\right)=0 .
\end{gathered}
$$

Proof of Proposition 4. The Hessian matrixes of $\Pi_{R_{1}}^{\mathrm{TR}}$ and $\Pi_{R_{2}}^{\mathrm{TR}}$ are

$$
H_{R_{1}}^{\mathrm{TR}}=H_{R_{2}}^{\mathrm{TR}}=\left(\begin{array}{cc}
-\frac{2}{\alpha} & 0 \\
0 & -\frac{2 \delta}{\beta}
\end{array}\right) .
$$

Since $\partial^{2} \Pi_{R_{1}}^{\mathrm{TR}} / \partial q_{1 n}{ }^{2}=\partial^{2} \Pi_{R_{1}}^{\mathrm{TR}} / \partial q_{1 n}{ }^{2}=-2 / \alpha<0$ and $\left|H_{R_{1}}^{\mathrm{TR}}\right|=\left|H_{R_{2}}^{\mathrm{TR}}\right|=4 \delta / \alpha \beta>0, \Pi_{R_{1}}^{\mathrm{TR}}$ is jointly concave in $q_{1 n}$ and $q_{1 t}$ and $\Pi_{R_{2}}^{\mathrm{TR}}$ is concave in $q_{2 n}$ and $q_{2 t}$. 
The first-order derivatives can be solved as follows:

$$
\begin{aligned}
& \frac{\partial \Pi_{R_{1}}^{\mathrm{SR}}}{\partial q_{1 n}}=1-w-\frac{2 q_{1 n}}{\alpha}-\frac{q_{2 n}}{\alpha}=0 . \\
& \frac{\partial \Pi_{R_{1}}^{\mathrm{SR}}}{\partial q_{1 t}}=s+\delta-w+v-\frac{2 \delta q_{1 t}}{\beta}-\frac{\delta q_{2 t}}{\beta}=0 \\
& \frac{\partial \Pi_{R_{2}}^{\mathrm{SR}}}{\partial q_{2 n}}=1-w-\frac{2 q_{2 n}}{\alpha}-\frac{q_{1 n}}{\alpha}=0 \\
& \frac{\partial \Pi_{R_{2}}^{\mathrm{SR}}}{\partial q_{2 t}}=s+\delta-w+v-\frac{2 \delta q_{2 t}}{\beta}-\frac{\delta q_{1 t}}{\beta}=0
\end{aligned}
$$

Then, taking the second-order derivative of $\Pi_{M}^{\mathrm{TR}}$ with respect to $w$, we can obtain $\partial^{2} \Pi_{M}^{\mathrm{TR}} / \partial w^{2}=-4 \alpha / 3-4 \beta / 3 \delta<0$; thus $\Pi_{M}^{\mathrm{TR}}$ is concave in $w$. And the optimal price strategy can be solved as follows:

$$
\begin{gathered}
\frac{\partial \Pi_{M}^{\mathrm{TR}}}{\partial w}=\frac{2 \alpha(1-w)}{3}+\frac{2 \beta(s+\delta+v-w)}{3 \delta} \\
-\left(\frac{2 \alpha}{3}+\frac{2 \beta}{3 \delta}\right)\left(w-c_{n}\right)=0 .
\end{gathered}
$$

Proof of Corollary 5. With the condition $b>1-\delta$, the following results can be obtained by comparing the equilibrium results:

$$
\begin{aligned}
& \frac{w^{\mathrm{TR} *}}{w^{\mathrm{SR} *}} \\
& =\frac{\left[\delta \alpha\left(1+c_{n}\right)+\beta\left(s+\delta+v+c_{n}\right)\right](4 \delta \alpha+3 \beta)}{\left[4 \delta \alpha\left(1+c_{n}\right)+3 \beta\left(s+\delta+v+c_{n}\right)\right](\delta \alpha+\beta)} \\
& >1, \\
& \frac{w^{\mathrm{SR} *}}{w^{\mathrm{M} *}}=\frac{4 \delta \alpha\left(1+c_{n}\right)+3 \beta\left(s+\delta+v+c_{n}\right)}{\left(1+c_{n}\right)(4 \delta \alpha+3 \beta)}>1 .
\end{aligned}
$$

$=\frac{\left[\delta \alpha^{2}\left(1-c_{n}\right)+\alpha \beta\left(2-s-\delta-v-c_{n}\right)\right](4 \delta \alpha+3 \beta)}{\left[4 \delta \alpha^{2}\left(1-c_{n}\right)+3 \alpha \beta\left(2-s-\delta-v-c_{n}\right)\right](\delta \alpha+\beta)}$

$<1$.

Hence, $Q_{n}^{\mathrm{M} *}>Q_{n}^{\mathrm{SR} *}>Q_{n}^{\mathrm{TR} *}$.

If $b>\left(1+c_{n}\right) / 2-\delta \alpha\left(1-c_{n}\right) / 2 \beta-\delta$ is satisfied, then

$\frac{Q_{n}^{\mathrm{TR} *}}{Q_{n}^{\mathrm{C} *}}=\frac{2 \delta \alpha\left(1-c_{n}\right)+2 \beta\left(2-s-\delta-v-c_{n}\right)}{\alpha\left(1-c_{n}\right)(3 \delta \alpha+3 \beta)}<1$.

Therefore, $Q_{n}^{\mathrm{C} *}>Q_{n}^{\mathrm{TR} *}$.

If $b>\left(1+c_{n}\right) / 2-2 \delta \alpha\left(1-c_{n}\right) / 3 \beta-\delta$ is satisfied, then

$$
\frac{Q_{n}^{\mathrm{TR} *}}{Q_{n}^{\mathrm{C} *}}=\frac{8 \delta \alpha\left(1-c_{n}\right)+6 \beta\left(2-s-\delta-v-c_{n}\right)}{\left(1-c_{n}\right)(12 \delta \alpha+9 \beta)}<1 .
$$

Hence, $Q_{n}^{\mathrm{C} *}>Q_{n}^{\mathrm{SR} *}$ can be derived.

Proof of Corollary 7. In a similar manner to the proof of Corollary 6,

$$
\begin{aligned}
\frac{Q_{t}^{\mathrm{SR} *}}{Q_{t}^{\mathrm{TR} *}}=\frac{\left[4 \delta \alpha \beta\left(2 s+2 \delta+2 v-c_{n}-1\right)+3 \beta^{2}\left(s+\delta+v-c_{n}\right)\right]\left(3 \delta^{2} \alpha+3 \delta \beta\right)}{\left[\delta \alpha \beta\left(2 v+2 \delta+2 s-c_{n}-1\right)+\beta^{2}\left(s+\delta+v-c_{n}\right)\right]\left(16 \delta^{2} \alpha+12 \delta \beta\right)}<1, \\
\frac{Q_{t}^{\mathrm{SR} *}}{Q_{t}^{\mathrm{M} *}}=\frac{4 \delta \alpha \beta\left(2 s+2 \delta+2 v-c_{n}-1\right)+3 \beta^{2}\left(s+\delta+v-c_{n}\right)}{\beta\left(v+\delta+s-c_{n}\right)(8 \delta \alpha+6 \beta)}<1 .
\end{aligned}
$$

Thus, we can obtain $Q_{t}^{\mathrm{TR} *}>Q_{t}^{\mathrm{SR} *}, Q_{t}^{\mathrm{M} *}>Q_{t}^{\mathrm{SR} *}$. Comparing $Q_{t}^{\mathrm{TR} *}$ and $Q_{t}^{\mathrm{M} *}$,

$$
\begin{aligned}
& \frac{Q_{t}^{\mathrm{TR} *}}{Q_{t}^{\mathrm{M} *}} \\
& =\frac{2 \delta \alpha\left(2 s+2 \delta+2 v-c_{n}-1\right)+2 \beta\left(s+\delta+v-c_{n}\right)}{\left(v+\delta+s-c_{n}\right)(3 \delta \alpha+3 \beta)}
\end{aligned}
$$

$>1$.

After simplification, this reduces to showing that

$$
(\delta \alpha-\beta) b>\delta \alpha\left(2-\delta-c_{n}\right)+\beta\left(\delta-c_{n}\right) .
$$

Then if $\delta \alpha>\beta$, and $b<2 \delta \alpha /(\delta \alpha-\beta)+c_{n}-\delta$ is satisfied, then $Q_{t}^{\mathrm{TR} *}>Q_{t}^{\mathrm{M} *}$; while if $\delta \alpha<\beta$, then $Q_{t}^{\mathrm{TR} *}<Q_{t}^{\mathrm{M} *}$. 
Proof of Corollary 8. The proof of Corollary 8 is similar to the proof of Corollary 7.

Proof of Corollary 9. To prove $\Pi_{M}^{\mathrm{SR} *}<\Pi_{M}^{\mathrm{TR} *}$, we have to show that

$$
\begin{aligned}
& \frac{\Pi_{M}^{\mathrm{SR} *}}{\Pi_{M}^{\mathrm{TR} *}} \\
& =\frac{\left[4 \delta \alpha\left(1-c_{n}\right)+3 \beta\left(v+\delta+s-c_{n}\right)\right]^{2}\left(\delta^{2} \alpha+\delta \beta\right)}{\left[\delta \alpha\left(1-c_{n}\right)+\beta\left(v+\delta+s-c_{n}\right)\right]^{2}\left(16 \delta^{2} \alpha+12 \delta \beta\right)}
\end{aligned}
$$

$<1$.

After simplification, this reduces to showing that

$$
\begin{aligned}
& \left(7 \delta \alpha \beta^{2}+3 \beta^{3}\right)\left(v+s+\delta-c_{n}\right)^{2} \\
& \quad+8 \delta^{2} \alpha^{2} \beta\left(1-c_{n}\right)\left(v+s+\delta-c_{n}\right) \\
& \quad-4 \delta^{2} \alpha^{2} \beta\left(1-c_{n}\right)^{2}>0 .
\end{aligned}
$$

We assume that $X=v+s+\delta-c_{n}$; then

$$
X>\frac{4 \delta \alpha\left(1-c_{n}\right)[\sqrt{(4 \delta \alpha+3 \beta)(\delta \alpha+\beta)}-2 \delta \alpha]}{2\left(7 \delta \alpha \beta+3 \beta^{2}\right)} .
$$

And we can obtain that if $>\quad c_{n}+4 \delta \alpha(1-$ $\left.c_{n}\right)[\sqrt{(4 \delta \alpha+3 \beta)(\delta \alpha+\beta)}-2 \delta \alpha] / 2\left(7 \delta \alpha \beta+3 \beta^{2}\right)-\delta$, then $\Pi_{M}^{\mathrm{SR} *}<\Pi_{M}^{\mathrm{TR} *}$.

Proof of Corollaries 10 and 11. The proofs of Corollaries 10 and 11 are similar to the proof of Corollary 9.

\section{Notations}

\section{Parameters and Definitions}

$w$ : The unit wholesale price

$p_{n}: \quad$ The unit retail price from the retailers to consumers

$p_{0}$ : The unit trade-in rebate from the manufacturer/the retailers to consumers

$p_{t}$ : The discount price when selling new products directly from the manufacturer to consumers

$c_{n}$ : The unit cost of manufacturing new products by the manufacturer

$Q_{n}, Q_{t}$ : The total demand of primary consumers and replacement consumers, respectively

$q_{1 n}, q_{2 n}$ : The demand of primary consumers from the retailer 1 and the retailer 2 , respectively

$q_{1 t}, q_{2 t}$ : The demand of replacement consumers from the retailer 1 and the retailer 2 , respectively

$\theta$ : The consumers' willingness to pay for new products

$\delta: \quad$ The quality retention index

$s$ : $\quad$ The unit government subsidy of a used product $v$ : The unit salvage value of a used product

$\Pi_{i}^{k}$ : The profit of channel member $i$ in Model $k$.

The superscript $k$ takes the value of Model C, M, SR, and TR, denoting centralized model, the model of manufacturer trade-in, single retailer trade-in, and two retailers trade-in, respectively. Here the subscript $i$ takes the value of $\mathrm{M}, R_{1}$, and $R_{2}$, which means the parameter corresponding to the manufacturer, the retailer 1 , and the retailer 2 , respectively.

\section{Conflicts of Interest}

The author declares no conflicts of interest.

\section{Acknowledgments}

This research is supported partially by the Enterprise Technology Innovation Soft Science Research Base of Hubei province, China (2014BDF002).

\section{References}

[1] J. Gönsch, "A note on a model to evaluate acquisition price and quantity of used products for remanufacturing," International Journal of Production Economics, vol. 169, pp. 277-284, 2015.

[2] C.-H. Chuang, C. X. Wang, and Y. Zhao, "Closed-loop supply chain models for a high-tech product under alternative reverse channel and collection cost structures," International Journal of Production Economics, vol. 156, pp. 108-123, 2014.

[3] A. Atasu and G. C. Souza, "How does product recovery affect quality choice?" Production Engineering Research and Development, vol. 22, no. 4, pp. 991-1010, 2013.

[4] M. Huang, M. Song, L. H. Lee, and W. K. Ching, "Analysis for strategy of closed-loop supply chain with dual recycling channel," International Journal of Production Economics, vol. 144 , no. 2, pp. 510-520, 2013.

[5] B. C. Giri, A. Chakraborty, and T. Maiti, "Pricing and return product collection decisions in a closed-loop supply chain with dual-channel in both forward and reverse logistics," Journal of Manufacturing Systems, vol. 42, pp. 104-123, 2017.

[6] A. Atasu, M. Sarvary, and L. N. V. Wassenhove, "Remanufacturing as a marketing strategy," Management Science, vol. 54, no. 10, pp. 1731-1746, 2008.

[7] T. Maiti and B. C. Giri, "A closed loop supply chain under retail price and product quality dependent demand," Journal of Manufacturing Systems, vol. 37, pp. 624-637, 2015.

[8] C.-H. Wu, "Price and service competition between new and remanufactured products in a two-echelon supply chain," International Journal of Production Economics, vol. 140, no. 1, pp. 496-507, 2012.

[9] V. D. R. Guide Jr. and L. N. van Wassenhove, "The evolution of closed-loop supply chain research," Operations Research, vol. 57, no. 1, pp. 10-18, 2009.

[10] A. Atasu and L. N. Van Wassenhove, "An operations perspective on product take-back legislation for E-waste: Theory, practice, and research needs," Production Engineering Research and Development, vol. 21, no. 3, pp. 407-422, 2012. 
[11] A. Atasu, L. N. Van Wassenhove, and M. Sarvary, "Efficient take-back legislation," Production Engineering Research and Development, vol. 18, no. 3, pp. 243-258, 2009.

[12] C.-H. Wu and H.-H. Wu, "Competitive remanufacturing strategy and take-back decision with OEM remanufacturing," Computers \& Industrial Engineering, vol. 98, pp. 149-163, 2016.

[13] S. Ray, T. Boyaci, and N. Aras, "Optimal prices and trade-in rebates for durable, remanufacturable products," Manufacturing and Service Operations Management, vol. 7, no. 3, pp. 208-228, 2005.

[14] K. J. Li and S. H. Xu, "The comparison between trade-in and leasing of a product with technology innovations," OMEGA The International Journal of Management Science, vol. 54, pp. 134-146, 2015.

[15] R. C. Savaskan, S. Bhattacharya, and L. N. Van Wassenhove, "Closed-loop supply chain models with product remanufacturing," Management Science, vol. 50, no. 2, pp. 239-252, 2004.

[16] D. Cole, B. Kazaz, and S. Webster, "Final purchase and tradein decisions in response to a component phase-out announcement: A deterministic analysis," International Journal of Production Research, vol. 54, no. 5, pp. 1257-1272, 2016.

[17] R. Yin, H. Li, and C. S. Tang, "Optimal pricing of two successivegeneration products with trade-in options under uncertainty," Decision Sciences, vol. 46, no. 3, pp. 565-595, 2015.

[18] J. Gao, H. Han, L. Hou, and H. Wang, "Pricing and effort decisions in a closed-loop supply chain under different channel power structures," Journal of Cleaner Production, vol. 112, pp. 2043-2057, 2016.

[19] Y. Zhou, Y. Xiong, G. Li, Z. Xiong, and M. Beck, “The bright side of manufacturing-remanufacturing conflict in a decentralised closed-loop supply chain," International Journal of Production Research, vol. 51, no. 9, pp. 2639-2651, 2013.

[20] S. Mitra, "Models to explore remanufacturing as a competitive strategy under duopoly," OMEGA - The International Journal of Management Science, vol. 59, pp. 215-227, 2016.

[21] C.-C. Hsieh, Y.-L. Chang, and C.-H. Wu, "Competitive pricing and ordering decisions in a multiple-channel supply chain," International Journal of Production Economics, vol. 154, pp. 156165, 2014.

[22] G. Ferrer and J. M. Swaminathan, "Managing new and remanufactured products," Management Science, vol. 52, no. 1, pp. 1526, 2006.

[23] A. Örsdemir, E. Kemahlıŏlu-Ziya, and A. K. Parlaktürk, "Competitive quality choice and remanufacturing," Production \& Operations Management, vol. 23, no. 1, pp. 48-64, 2014.

[24] C.-H. Wu, "Strategic and operational decisions under sales competition and collection competition for end-of-use products in remanufacturing," International Journal of Production Economics, vol. 169, pp. 11-20, 2015.

[25] Q. Qiang, “The closed-loop supply chain network with competition and design for remanufactureability," Journal of Cleaner Production, vol. 105, pp. 348-356, 2015.

[26] R. C. Savaskan and L. N. van Wassenhove, "Reverse channel design: the case of competing retailers," Management Science, vol. 52, no. 1, pp. 1-14, 2006.

[27] J. Wei and J. Zhao, "Pricing decisions with retail competition in a fuzzy closed-loop supply chain," Expert Systems with Applications, vol. 38, no. 9, pp. 11209-11216, 2011.

[28] J. Wei and J. Zhao, "Pricing and remanufacturing decisions in two competing supply chains," International Journal of Production Research, vol. 53, no. 1, pp. 258-278, 2014.
[29] W.-m. Ma, Z. Zhao, and H. Ke, "Dual-channel closed-loop supply chain with government consumption-subsidy," European Journal of Operational Research, vol. 226, no. 2, pp. 221-227, 2013.

[30] Z. Miao, K. Fu, Z. Xia, and Y. Wang, "Models for closedloop supply chain with trade-ins," OMEGA - The International Journal of Management Science, vol. 66, pp. 308-326, 2017.

[31] Z. Miao, H. Mao, K. Fu, and Y. Wang, "Remanufacturing with trade-ins under carbon regulations," Computers \& Operations Research, 2016.

[32] X. Zhu, M. Wang, G. Chen, and X. Chen, "The effect of implementing trade-in strategy on duopoly competition," European Journal of Operational Research, vol. 248, no. 3, pp. 856-868, 2016.

[33] Y. Xiong, Q. Zhao, and Y. Zhou, "Manufacturerremanufacturing vs supplier-remanufacturing in a closed-loop supply chain," International Journal of Production Economics, vol. 176, pp. 21-28, 2016. 


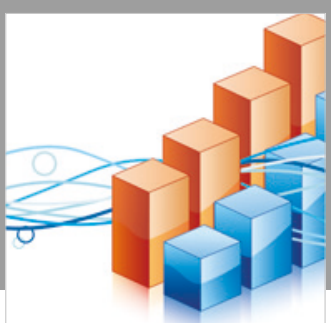

Advances in

Operations Research

\section{-n-m}
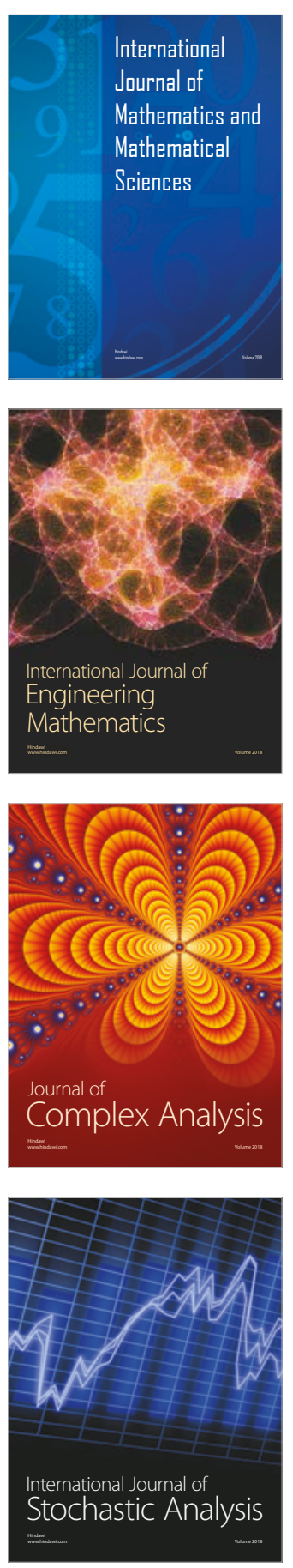
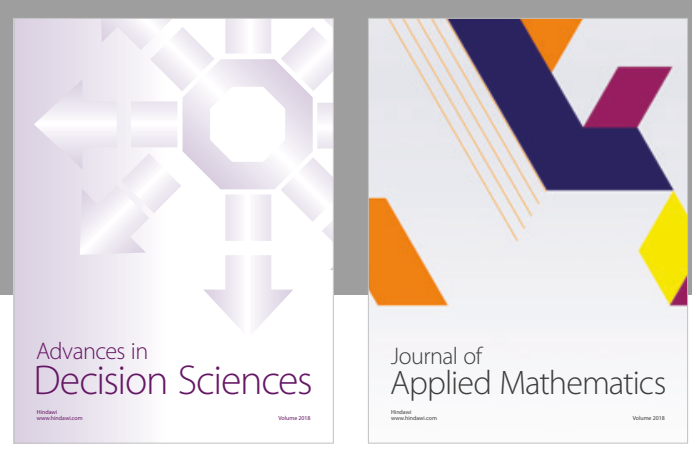

Journal of

Applied Mathematics
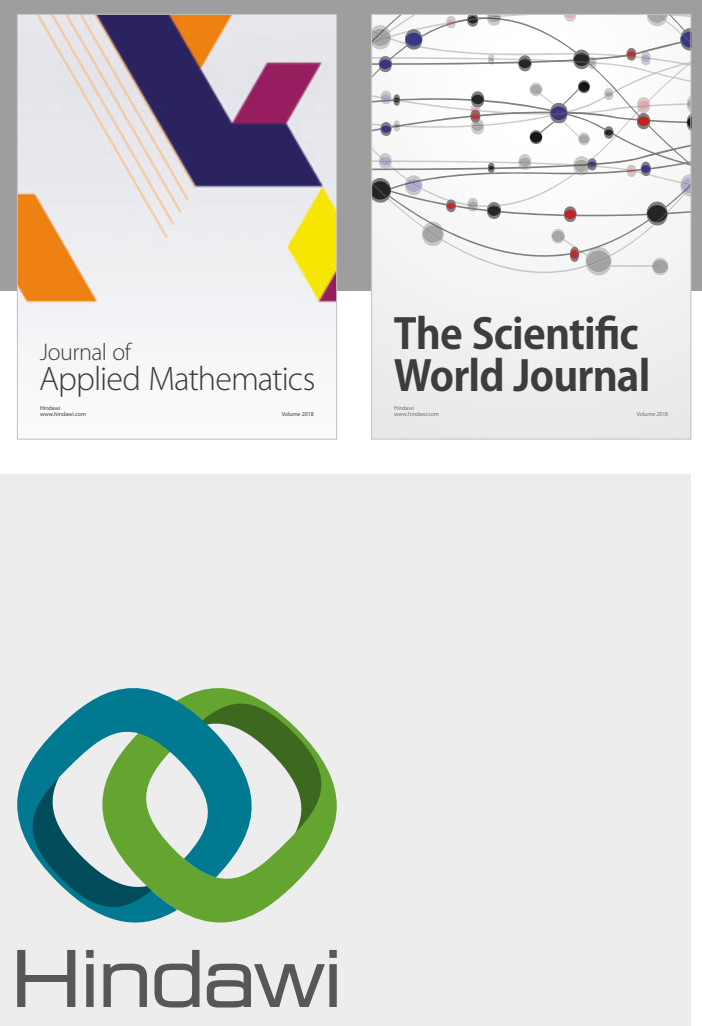

Submit your manuscripts at

www.hindawi.com

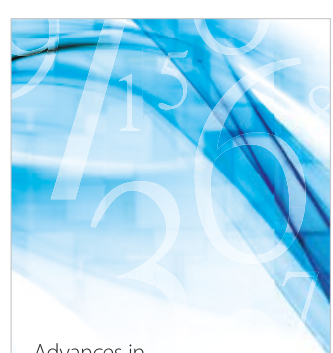

Advances in
Numerical Analysis
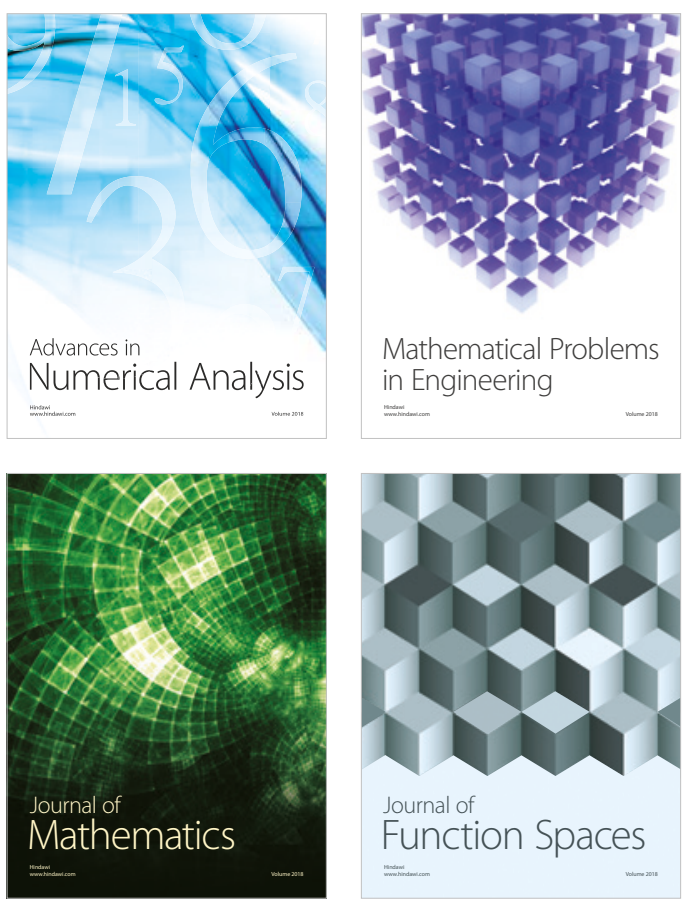

Mathematical Problems in Engineering

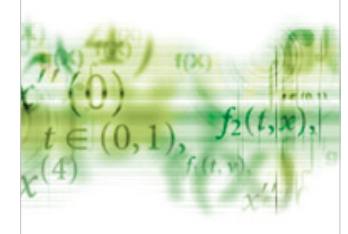

International Journal of

Differential Equations

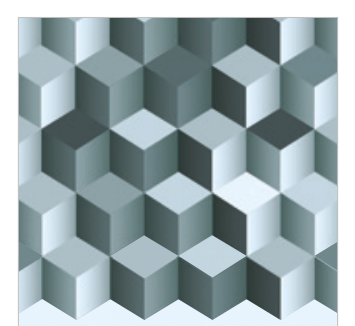

Journal of

Function Spaces
The Scientific

World Journal

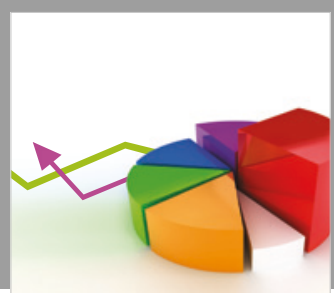

Journal of

Probability and Statistics
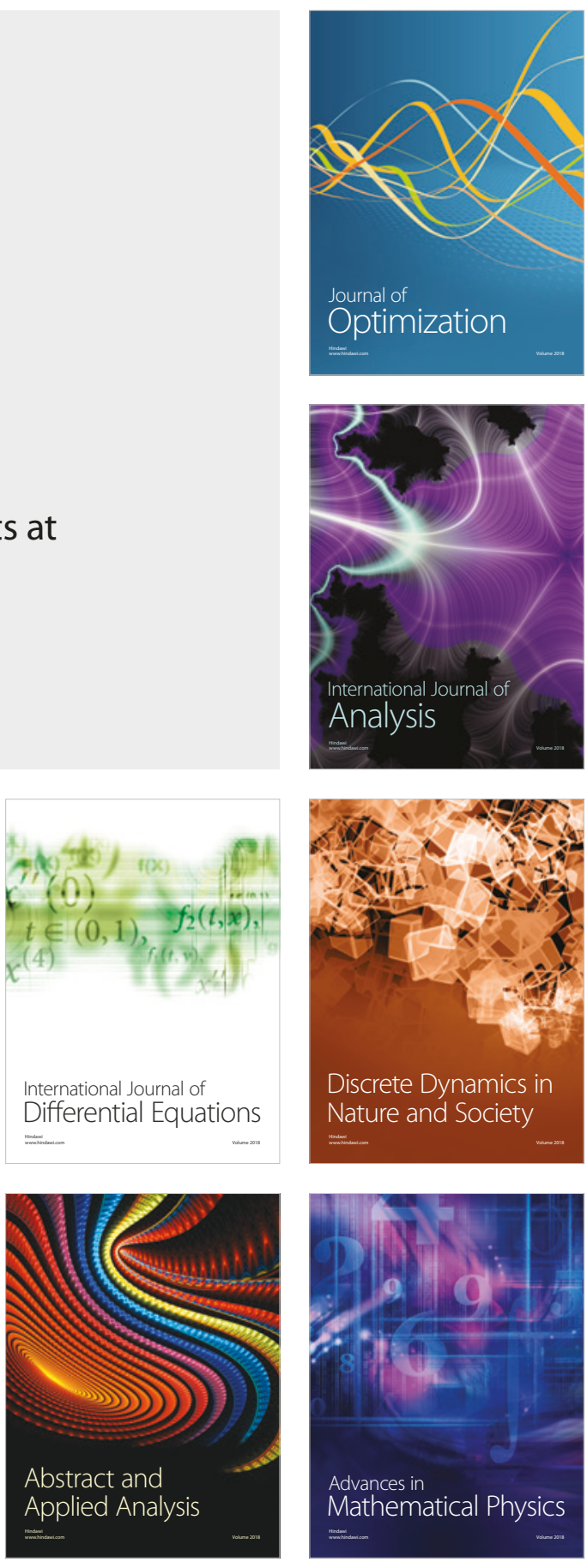